\title{
An eddy-permitting coupled physical-biological model of the North Atlantic \\ 1. Sensitivity to advection numerics and mixed layer physics
}

\author{
Andreas Oschlies ${ }^{1}$ \\ Institut für Meereskunde an der Universität Kiel, Kiel, Germany \\ Veronique Garçon \\ Centre National de la Recherche Scientifique, UMR5566/LEGOS, Toulouse, France
}

\begin{abstract}
Physical influences on biological primary production in the North Atlantic are investigated by coupling a four-component pelagic ecosystem model with a high-resolution numerical circulation model. A series of sensitivity experiments demonstrates the important role of an accurate formulation of upper ocean turbulence and advection numerics. The unrealistically large diffusivity implicit in upstream advection approximately doubles primary production when compared with a less diffusive, higher-order, positive-definite advection scheme. This is of particular concern in the equatorial upwelling region where upstream advection leads to a considerable increase of upper ocean nitrate concentrations. Counteracting this effect of unrealistically large implicit diffusion by changes in the biological model could easily lead to misconceptions in the interpretation of ecosystem dynamics. Subgrid-scale diapycnal diffusion strongly controls biological production in the subtropical gyre where winter mixing does not reach the nutricline. The parameterization of vertical viscosity is important mainly in the equatorial region where friction becomes an important agent in the momentum balance.
\end{abstract}

\section{Introduction}

In contrast to terrestrial ecosystems, which can, to a large extent, rely on gravity in getting back dead organic material, upper open ocean ecosystems are in the unfavorable position that particulate organic matter tends to sink out of the well-lit euphotic zone into the dark ocean interior. Growth of phytoplankton, however, requires the presence of both light and nutrients. By creating particles that may sink through the water instead of moving with it, pelagic ecosystems can, on the other hand, effectively separate regions of photosynthetic uptake of carbon dioxide from its release during respiration. The corresponding reduction of $\mathrm{CO}_{2}$ in the surface waters modulates the partial pressure difference

\footnotetext{
${ }^{1}$ Formerly at Centre National de la Recherche Scientifique, UMR5566/LEGOS, Toulouse, France.

Copyright 1999 by the American Geophysical Union.

Paper number 98GB02811.

0886-6236/99/98GB-02811\$12.00
}

and hence the flux of $\mathrm{CO}_{2}$ between the atmosphere and the surface ocean [e.g., Watson et al., 1991].

Nutrients can be supplied to the upper ocean by various physical transport mechanisms. Coastal and open ocean upwelling, episodic mixing up of deep water, e.g., by winter convection, continuous diapycnal diffusion in the nutricline, and eddy-induced vertical motions can all contribute to fueling biological production in the surface ocean. Physical processes also govern the depth of the turbulent surface mixed layer. In deep winter mixed layers in midlatitude and high-latitude regions, phytoplankton may not remain in the euphotic zone long enough for growth to take place. Stabilization of the surface layer in spring can then give rise to sudden blooms of algae.

The conditions for biological production in the open surface ocean are thus intimately dependent on a variety of physical processes. To fully understand the ocean's role in the global carbon cycle, it is of fundamental importance to identify those factors that control spatial and temporal variability of oceanic primary and export production. In the present study this demanding task, which requires synoptic descriptions of the ocean's 
state, is approached by using an eddy-permitting model of the North Atlantic circulation which sets the physical environment for a simple four-component nitratephytoplankton-zooplankton-detritus (N-P-Z-D) pelagic ecosystem. We selected this simple biological model since our goal is to understand the impact of physical processes and their representation in a numerical model on the biology, rather than to simulate ecological complexity. The novel aspect of our work as compared to previous investigations dealing with idealized eddyresolving models [e.g., Dadou et al., 1996; McGillicuddy and Robinson, 1997] is the realistic physical environment provided for an entire ocean basin.

As a first step, we investigate primarily the coupled model's sensitivity to different representations of tracer advection and turbulent diffusion. In section 2 we describe the primitive equation ocean general circulation model, two alternative parameterizations of the surface mixed layer, and the nitrogen-based model of ecosystem dynamics. Section 3 is devoted to a series of sensitivity studies to investigate the coupled model's sensitivity to parameters of the biological equations as well as to the choice of the mixed layer formulation and advection numerics. On the base of our sensitivity experiments we then select a "baseline" experiment in section 4 . Part 2 of our study (A. Oschlies et al., manusript in preparation, 1998) will then be devoted to a detailed analysis of the ecosystem dynamics of this standard run. The effect of explicitly resolving eddies on new and primary production is investigated in a separate paper [Oschlies and Garçon, 1998].

\section{Coupled Model}

\subsection{Physical Model}

The physical model is based on the Geophysical Fluid Dynamics Laboratory (GFDL) Modular Ocean Model (MOM), (version 1.1) [Pacanowski et al., 1991]. In the configuration set up for the Community Modeling Effort (CME) by Bryan and Holland [1989] it covers the Atlantic Ocean between $15^{\circ} \mathrm{S}$ and $65^{\circ} \mathrm{N}$ with a grid spacing of $1 / 3^{\circ}$ in meridional and $2 / 5^{\circ}$ in zonal directions. Stammer and Böning [1992] found that the eddy scales simulated by the CME model were in good agreement with Geosat altimeter data in the tropics and subtropics. They were systematically larger than the observed scales at higher latitudes north of about $30^{\circ} \mathrm{N}$, where the first baroclinic Rossby radius of deformation is not well resolved by the model grid. Instead of "eddy resolving," we conservatively use the term "eddy permitting" for the present model configuration.

Northern and southern lateral boundaries are closed as is the Strait of Gibraltar, with buffer zones five grid points wide at which the temperature and salinity of the water are relaxed to values taken from the Levitus [1982] atlas, except for deep levels in the Denmark Strait where conductivity-temperature-depth (CTD) station data are used to account for the signature of Denmark Strait Overflow Water [Döscher et al., 1994]. An additional restoring zone exists off the Labrador shelf to correct for the missing sea-ice model and to prevent the model from producing unrealistically cold water in winter.

A simulation of pelagic biological processes requires a fine vertical resolution to accurately model sharp vertical gradients of biological tracer concentrations in and just below the euphotic zone. Following a suggestion of F. Bryan (personal communication, 1994) we simply divided original CME grid boxes into two or three, with no changes being made to the model topography. Altogether, seven additional levels were introduced, in-

Table 1. Vertical Levels of the Numerical Model

\begin{tabular}{|c|c|c|c|}
\hline $\begin{array}{l}\text { Model } \\
\text { Level }\end{array}$ & $\begin{array}{l}\text { Depth of } \\
\text { Grid Point }\end{array}$ & $\begin{array}{c}\text { Depth of } \\
\text { Grid Box } \\
\text { Bottom }\end{array}$ & $\begin{array}{c}\text { Thickness of } \\
\text { Grid Box }\end{array}$ \\
\hline 1 & 5.50 & 11.00 & 11.00 \\
\hline 2 & 17.00 & 23.00 & 12.00 \\
\hline 3 & 29.00 & 35.00 & 12.00 \\
\hline 4 & 41.00 & 47.00 & 12.00 \\
\hline 5 & 53.00 & 59.00 & 12.00 \\
\hline 6 & 65.50 & 72.00 & 13.00 \\
\hline 7 & 78.50 & 85.00 & 13.00 \\
\hline 8 & 91.50 & 98.00 & 13.00 \\
\hline 9 & 104.50 & 111.00 & 13.00 \\
\hline 10 & 118.50 & 126.00 & 15.00 \\
\hline 11 & 140.50 & 155.00 & 29.00 \\
\hline 12 & 179.55 & 204.09 & 49.09 \\
\hline 13 & 232.60 & 261.10 & 57.01 \\
\hline 14 & 295.03 & 328.95 & 67.85 \\
\hline 15 & 370.21 & 411.47 & 82.52 \\
\hline 16 & 462.51 & 513.54 & 102.07 \\
\hline 17 & 577.37 & 641.19 & 127.65 \\
\hline 18 & 721.47 & 801.74 & 160.55 \\
\hline 19 & 900.89 & 1000.04 & 198.30 \\
\hline 20 & 1125.04 & 1250.04 & 250.00 \\
\hline 21 & 1375.04 & 1500.04 & 250.00 \\
\hline 22 & 1625.04 & 1750.04 & 250.00 \\
\hline 23 & 1875.04 & 2000.04 & 250.00 \\
\hline 24 & 2125.04 & 2250.04 & 250.00 \\
\hline 25 & 2375.04 & 2500.04 & 250.00 \\
\hline 26 & 2625.04 & 2750.04 & 250.00 \\
\hline 27 & 2875.04 & 3000.04 & 250.00 \\
\hline 28 & 3125.04 & 3250.04 & 250.00 \\
\hline 29 & 3375.04 & 3500.04 & 250.00 \\
\hline 30 & 3625.04 & 3750.04 & 250.00 \\
\hline 31 & 3875.04 & 4000.04 & 250.00 \\
\hline 32 & 4125.04 & 4250.04 & 250.00 \\
\hline 33 & 4375.04 & 4500.04 & 250.00 \\
\hline 34 & 4625.04 & 4750.04 & 250.00 \\
\hline 35 & 4875.04 & 5000.04 & 250.00 \\
\hline 36 & 5125.04 & 5250.04 & 250.00 \\
\hline 37 & 5375.04 & 5500.04 & 250.00 \\
\hline
\end{tabular}

Units are meters. 
creasing the number of levels in the upper $150 \mathrm{~m}$ from four to eleven (Table 1).

The model is forced with climatological data sets. In the present study, no attempt is made to resolve highfrequency forcing or the daily cycle. Monthly mean wind stresses $\langle\tau\rangle$ as well as the monthly mean of the third power of the friction velocity $\left\langle u_{*}^{3}\right\rangle$, where $u_{*}=$ $\left(|\tau| / \rho_{w}\right)^{1 / 2}$ in water of density $\rho_{w}$, are taken from Hellerman and Rosenstein [1983]. The thermohaline forcing is represented by a relaxation of surface salinity to the monthly mean values of Levitus [1982] and a heat flux given by the linear Haney [1971] formulation; instead of a relaxation of the model sea surface temperature (SST) toward the observed climatological SST, an approach followed, e.g., by Sarmiento et al. [1993] that would unrealistically result in vanishing surface heat transfer for perfect model SST fields, the downward heat flux into the ocean is expressed as

$$
Q_{\mathrm{NET}}\left(T_{\mathrm{surf}}\right)=Q_{\mathrm{SOL}}+Q_{\mathrm{NSOL}}+Q_{2}\left(T_{a}-T_{\text {surf }}\right)
$$

$Q_{\mathrm{SOL}}$ and $Q_{\mathrm{NSOL}}$ account for solar and nonsolar heat fluxes; $Q_{2}$ presents the net flux of longwave radiation as well as sensible and latent heat per degree Celsius deviation of the model surface temperature $T_{\text {surf }}$ from a climatological, seasonally varying atmospheric equilibrium temperature $T_{a}$. In general, $Q_{2}$ depends on $T_{a}$ and $Q_{\mathrm{NSOL}}$, but not on $Q_{\mathrm{SOL}}$ as there is no immediate feedback of surface temperature on solar radiation. The above relation can be rewritten as

$$
Q_{\mathrm{NET}}\left(T_{\text {surf }}\right)=Q_{2}\left(T^{*}-T_{\text {surf }}\right)
$$

or, equivalently,

$$
Q_{\mathrm{NET}}\left(T_{\text {surf }}\right)=Q_{\mathrm{SOL}}+Q_{2}\left(\hat{T}^{*}-T_{\text {surf }}\right)
$$

with

$$
\hat{T}^{*}=T^{*}-\frac{Q_{\mathrm{SOL}}}{Q_{2}} .
$$

Previous CME experiments used (2), with the prescribed monthly fields of $T^{*}$ and $Q_{2}$ computed as described by $\operatorname{Han}$ [1984]. In the present study we alternatively employ (3) to explicitly include the effect of penetrating shortwave solar radiation. This is consistent with the forcing of the biological model, which depends strongly on photosynthetically active radiation being available below the sea surface. It is also important for modeling the seasonal mixed layer cycle, which is strongly affected by subsurface heating due to penetrating solar radiation.

Climatological monthly mean shortwave heat fluxes are taken from the Barnier et al. [1995] analysis of the European Centre for Medium-Range Weather Forecasts (ECMWF) 1986 to 1988 data. The vertical profile of absorption of solar radiation is modeled by the analyt- ical formula of Paulson and Simpson [1977] for clear ocean water (type I [after Jerlov, 1968]). In the present study we have not attempted to model the feedback of phytoplankton concentration on the model physics owing to the absorption of solar radiation. As far as the thermal effect of penetrating shortwave radiation is concerned, we have used clear ocean water for the entire model domain. The self-shading of phytoplankton has, however, been taken into account in the radiation profile used to compute primary production within the biological model (see below). To account for changes in the solar incidence angle with latitude and season (but without resolving the daily cycle), the optical path of the shortwave radiation in water is assumed to be consistent with the solar elevation at noon and a refractive index of seawater of 1.33. The high noon incidence angle is thought to present a reasonable approximation of the daily mean incidence angle of the ECMWF shortwave fluxes which comprise both direct and diffuse sky radiation.

2.1.1. A reduced Kraus-Turner model. The mixed layer model that has for some time been in use in the CME model is a reduced version of the original Kraus-Turner bulk model [Kraus and Turner, 1967]. It treats the surface mixed layer as a homogeneous slab, its depth $h$ being determined from a balance equation of the turbulent kinetic energy (TKE) budget. In the present version, which closely follows the work of Camp and Elsberry [1978], all TKE generating processes are assumed to be proportional to the cube of the friction velocity (in the water) $u_{*}^{3}$. Dissipation of wind-induced TKE is also assumed to be proportional to $u_{*}^{3}$ with a coefficient of proportionality of $m_{1}\left(1-e^{-h / D}\right)$ (see Gaspar [1988], for a discussion of dissipation parameterizations). Contributions to the TKE production from surface buoyancy fluxes are not explicitly taken into account (i.e., nonpenetrative convection: TKE produced by buoyancy forces is completely dissipated within the mixed layer). The TKE budget then reads [e.g., Niiler and Kraus, 1977]

$$
\frac{1}{2} w_{e} \Delta b h=m_{1} u_{*}^{3} e^{-h / D}+\frac{h}{4}\left[B_{0}-\left|B_{0}\right|\right]
$$

where the first term on the right describes the production of TKE and is proportional to $u_{*}^{3}$ with the empirical constants $m_{1}=0.3$ and $D=50 \mathrm{~m}$. The second term on the right is negative for $B_{0}<0$ and is zero for positive buoyancy forcing $B_{0}$ (e.g., cooling). In contrast to one-dimensional models, here $B_{0}$ accounts also for advective and diffusive processes that change density within the mixed layer. The term on the left-hand side closes the TKE balance by adjusting the mixed layer depth $h$. If the right-hand side is positive, the net TKE gain of wind forcing minus stabilizing buoyancy forcing is converted into potential energy of the water column 
by deepening the mixed layer with an entrainment velocity $w_{e}$ and a buoyancy jump $\Delta b$ across the base of the mixed layer. The algorithm employed for solving the above balance equation on a discrete vertical grid follows Sterl and Kattenberg [1994]. Its implementation and some pecularities in conjunction with the time sequencing of mixed layer routine and convective adjustment are discussed by Oschlies [1998].

While earlier CME experiments used a vertical grid with a thickness of the uppermost box of $35 \mathrm{~m}$, the present model would concentrate the entire Ekman transport in the upper $11 \mathrm{~m}$ if no extra vertical mixing of momentum were applied. On the basis of observational evidence [e.g., Price et al., 1986] and previous model studies [e.g., Niiler and Kraus, 1977; Sterl and Kattenberg, 1994], we decided to homogenize not only tracer but also momentum over the depth $h$ (similarly, momentum was homogenized by the convective adjustment scheme). Since the more elaborate turbulence closure scheme presented in the following section also leads to approximate homogenization of momentum in the mixed layer, momentum mixing in the Kraus-Turner type model is regarded as the natural choice to facilitate comparison of the two mixed layer models.

Below the surface mixed layer, vertical diffusivity and viscosity are modeled in two alternative ways; one experiment employs constant exchange coefficients of $0.3 \mathrm{~cm}^{2} \mathrm{~s}^{-1}$ for diffusivity and $10 \mathrm{~cm}^{2} \mathrm{~s}^{-1}$ for viscosity. Another experiment was run with the same constant vertical viscosity, but the diffusion coefficients were computed by the formulation $K_{\rho}=a N^{-1}$, where $N$ is the Brunt-Väisälä frequency, as proposed by Gargett [1984]. To match recent observations of Ledwell et al. [1993], we chose $a=5.7 \times 10^{-4} \mathrm{~cm}^{2} \mathrm{~s}^{-2}$. We note that the TKE scheme presented below was tuned to converge to essentially the same vertical diffusion coefficients, $K_{\rho}=a N^{-1}$, in and below the thermocline.

2.1.2. The TKE closure. As an alternative to the simple Kraus-Turner type mixed layer model that treats the mixed layer as homogeneous slab with infinite diffusivity and, in the form presented above, accounts only for wind-induced turbulence, we also implemented a more elaborate turbulence closure model that considers additionally TKE generation by shear instabilities and buoyancy forcing as well as turbulent transport of TKE itself. In contrast to Kraus-Turner type integral mixed layer models, the TKE model computes finite diffusivities (and viscosities) at each depth level. Although turbulent mixing coefficients will be large in the mixed layer, this does not completely rule out the existence of some vertical structure of biological tracers, even within the mixed layer.

The TKE model was first described for oceanic applications by Gaspar et al. [1990]. It is used in the slightly modified and computationally more economic version presented by Blanke and Delecluse [1993]. The model solves a prognostic equation for the grid box TKE. Both the vertical viscosity $K_{m}$ as well as viscous dissipation of TKE $\epsilon$ are proportional to the local value of TKE

$$
\begin{aligned}
K_{m} & \sim \operatorname{TKE} N^{-1} \\
\epsilon & \sim \operatorname{TKE} N
\end{aligned}
$$

The vertical diffusivity is expressed as

$$
K_{\rho}=P_{r t}^{-1} K_{m}
$$

where $P_{r t}$ is the Prandtl number, which is parameterized as a function of the Richardson number $R i$ and varies linearly with $R i$ between $P_{r t}=1$ for $R i \leq 0.2$ (i.e., fully turbulent flow) and $P_{r t}=10$ for $R i \geq 5$ (laminar flow). The vertical exchange coefficient of TKE is set to $K_{e}=\alpha K_{m}$ with $\alpha=30$. The full TKE closure is described in detail by Blanke and Delecluse [1993], the only changes being a different lower limit for TKE and a surface flux condition $K_{e} \partial \bar{e} / \partial z=m u_{*}^{3}$, with $m=3$. The lower limit for TKE was set to $4 \times 10^{-2} \mathrm{~cm}^{2} \mathrm{~s}^{-2}$. This ensures that well below the pycnocline diffusivities converge to the same $K_{\rho}=a N^{-1}$ relation as used in one application of the Kraus-Turner model.

We finally note that in contrast to the Kraus-Turner type mixed layer model described in section 2.1.1, the TKE scheme computes vertical diffusivities for the entire water column. Therefore, it accounts automatically for the removal of static instabilities, and an extra routine for convective adjustment is not required. While using the TKE scheme is thus more economical with respect to CPU time requirements (in the present configuration, about $10 \%$ less than Kraus-Turner plus $K_{\rho}=a N^{-1}$ diffusivities), it needs extra memory space for the additional prognostic variable TKE.

\subsection{Biological Model}

There exists already a large variety of marine ecosystem models to simulate different biological processes, often in different marine environments. For this study we tried to formulate a single set of biological equations that is robust and computationally cheap enough to be coupled to a basin-wide eddy-permitting circulation model, covering subpolar and subtropical regions as well as the equatorial Atlantic. A marine ecosystem model set up explicitly with this purpose in mind was first presented in a zero-dimensional form by Fasham et al. [1990]. Results of its coupling into a coarse resolution model of the North Atlantic were given by Sarmiento et al. [1993] and Fasham et al. [1993].

The evolution of any biological tracer concentration $C_{i}$ is determined by an advective-diffusive equation

$$
\frac{\partial C_{i}}{\partial t}=-\nabla \cdot\left(\mathbf{u} C_{i}\right)-A_{\rho} \nabla^{4} C_{i}+\frac{\partial}{\partial z}\left(K_{\rho} \frac{\partial C_{i}}{\partial z}\right)+\operatorname{sms}\left(C_{i}\right)
$$




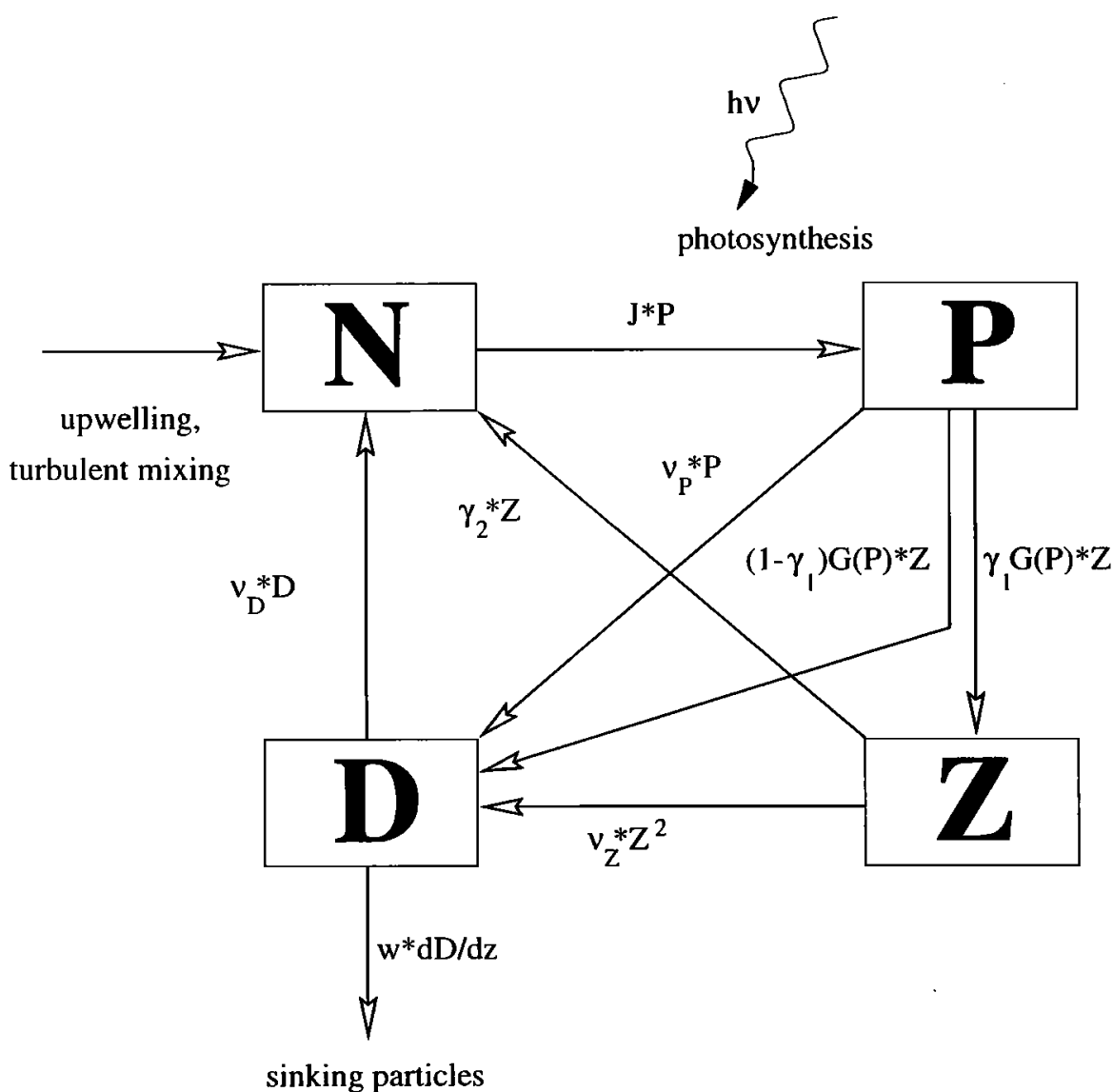

Figure 1. Compartments and interactions of the pelagic ecosystem. See text for a description of the individual terms.

where the first term on the right-hand side accounts for advection, the second accounts for (biharmonic) horizontal diffusion, and the third term represents vertical mixing with turbulent diffusion coefficient $K_{\rho}$. The last term is the source-minus-sink term due to biological activity. In our experiments described herein, more than $90 \%$ of the computational cost of (9) is spent on the advective and diffusive fluxes. Consequently, only little computer time could be gained by simplifying the source-minus-sink terms, and computational cost will be roughly proportional to the number of tracers. While the model of Fasham et al. [1990] consists of seven biological variables, we have reduced the number of biological tracers to four. In the present study we use a simple nitrogen-based N-P-Z-D pelagic model. For the individual biological tracers, the source-minus-sink terms are given (see also Figure 1) by

$$
\begin{aligned}
\operatorname{sms}(\mathrm{P})= & \bar{J}(z, t, \mathrm{~N}) \mathrm{P}-G(\mathrm{P}) \mathrm{Z}-\mu_{\mathrm{P}} \mathrm{P} \\
\operatorname{sms}(\mathrm{Z})= & \gamma_{1} G(\mathrm{P}) \mathrm{Z}-\gamma_{2} \mathrm{Z}-\mu_{\mathrm{Z}} \mathrm{Z}^{2} \\
\operatorname{sms}(\mathrm{D})= & \left(1-\gamma_{1}\right) G(\mathrm{P}) \mathrm{Z}+\mu_{\mathrm{P}} \mathrm{P}+\mu_{\mathrm{Z}} \mathrm{Z}^{2} \\
& -\mu_{\mathrm{D}} \mathrm{D}-w_{s} \frac{\partial \mathrm{D}}{\partial z}
\end{aligned}
$$

$$
\operatorname{sms}(\mathrm{N})=\mu_{\mathrm{D}} \mathrm{D}+\gamma_{2} \mathrm{Z}-\bar{J}(z, t, \mathrm{~N}) \mathrm{P}
$$

where $\bar{J}$ is the daily averaged phytoplankton growth rate as a function of depth $z$ and time $t$, and $G$ is the grazing function (see below). The remaining parameters in the above equations are defined in Table 2. In contrast to the previous work of Sarmiento et al. [1993] who applied different ecosystem equations in and below the euphotic zone, we solved the above set of equations at each depth level down to the bottom. Particularly when the mixed layer depth exceeds that of the euphotic zone, a situation not uncommon in the subpolar North Atlantic, this approach seems to be more concise than solving two different sets of equations in different regions of a well-mixed water column.

The phytoplankton growth rate $\bar{J}(z, t)$ depends both on available photosynthetically active radiation (PAR) as well as on the concentration of nitrate $\mathrm{N}$ available. Following Hurtt and Armstrong [1996], we use the minimum of light- and nutrient-limited growth,

$$
\bar{J}(z, t, \mathrm{~N})=\min \left(\bar{J}(z, t), J_{\max } \frac{\mathrm{N}}{k_{1}+\mathrm{N}}\right)
$$


Table 2. Parameters of the Ecosystem Model

\begin{tabular}{|c|c|c|c|}
\hline Parameter & Symbol & Value & Units \\
\hline \multicolumn{4}{|c|}{ Phytoplankton $(P)$ Coefficients } \\
\hline $\begin{array}{l}\text { Integration method for daily growth rate } \\
\text { Initial slope of P-I curve } \\
\text { Photosynthetically active ratiation } \\
\text { Light attenuation due to water } \\
\text { Light attenuation by phytoplankton } \\
\text { Maximum growth rate parameters }\end{array}$ & $\begin{array}{c}\alpha \\
\text { PAR } \\
k_{w} \\
k_{c} \\
a \\
b \\
c \\
K_{1} \\
\mu_{P}\end{array}$ & $\begin{array}{c}\text { EP85 } \\
0.025 \\
0.43 \\
0.04 \\
0.03 \\
0.6 \\
1.066 \\
1.0 \\
0.5 \\
0.03\end{array}$ & $\begin{array}{c}\mathrm{d}^{-1} /\left(\mathrm{W} \mathrm{m}^{-2}\right) \\
\mathrm{m}^{-1}\left(\mathrm{mmolm}^{-1}\right)^{-1} \\
\mathrm{day}^{-1} \\
\left({ }^{\circ} \mathrm{C}\right)^{-1} \\
\mathrm{mmol} \mathrm{m}^{-3} \\
\text { day }^{-1}\end{array}$ \\
\hline \multicolumn{4}{|c|}{ Zooplankton (Z) Coefficients } \\
\hline $\begin{array}{l}\text { Assimilation efficiency } \\
\text { Maximum grazing rate } \\
\text { Prey capture rate } \\
\text { (Quadratic) mortality } \\
\text { Excretion }\end{array}$ & $\begin{array}{c}\gamma_{1} \\
g \\
\epsilon \\
\mu_{Z} \\
\gamma_{2}\end{array}$ & $\begin{array}{c}0.75 \\
2.0 \\
1.0 \\
0.20 \\
0.03\end{array}$ & $\begin{array}{c}\mathrm{day}^{-1} \\
\left(\mathrm{mmol} \mathrm{m}^{-3}\right)^{-2} \mathrm{~d}^{-1} \\
\left(\mathrm{mmol} \mathrm{m}^{-3}\right)^{-1} \mathrm{~d}^{-1} \\
\mathrm{day}^{-1}\end{array}$ \\
\hline \multicolumn{4}{|c|}{ Detrital (D) Coefficients } \\
\hline $\begin{array}{l}\text { Remineralization rate } \\
\text { Sinking velocity }\end{array}$ & $\begin{array}{l}\mu_{D} \\
w_{s}\end{array}$ & $\begin{array}{c}0.05 \\
5.0\end{array}$ & $\begin{array}{l}\text { day }^{-1} \\
\mathrm{md}^{-1}\end{array}$ \\
\hline
\end{tabular}

EP85 is Evans and Parslow [1985].

where $\bar{J}(z, t)$ denotes the purely light-limited growth rate, and $J_{\max }$ is the light-saturated growth. The minimum principle, going back to von Liebig [1840], was preferred to the often used product of light- and nutrientlimitation terms because it may later be used to recalculate a variable chlorophyll-to-nitrogen ratio depending on the limiting factors that control the growth of a given phytoplankton population. This may be important for assimilation of ocean color measurements.

Since we do not intend to model the diurnal cycle, the actual light-limited growth rate $J(z, t)$ is averaged in time over $\tau_{24 \mathrm{~h}}=1$ day and in the vertical over one grid box, yielding

$$
\bar{J}(z, t)=\frac{1}{\tau_{24 \mathrm{~h}}} \int_{0}^{24 \mathrm{~h}} \frac{1}{z_{k}-z_{k+1}} \int_{z_{k+1}}^{z_{k}} J(z, t) d z d t
$$

where

$$
\begin{gathered}
J(z, t)=\frac{V_{p} \alpha I(z, t)}{\left[V_{p}^{2}+(\alpha I(z, t))^{2}\right]^{1 / 2}} \\
I(z, t)=I(t)_{z=0} e^{\left(k_{w} \tilde{z}-\int_{\bar{z}}^{0} k_{c} \mathrm{P} d z\right)} \\
I(t)_{z=0}=\operatorname{PAR} \tau(t) 2 \frac{\tau_{24 \mathrm{~h}}}{\tau_{\mathrm{sun}}} I_{\mathrm{ECMWF}}(t) \\
J_{\max }=V_{p}=a b^{c T}
\end{gathered}
$$

Here $\tilde{z}=z / \sqrt{1-(\cos \theta / 1.33)^{2}}$ is the effective vertical coordinate with the angle $\theta$ of incidence at noon and $\tau(t)$ is a triangle function describing the evolution of the day, increasing linearly from 0 to 1 from daybreak to noon and decreasing linearly to 0 at nightfall over the variable day length $\tau_{\text {sun }}$ calculated from astronomical parameters. The integral (15) is solved analytically as described by Evans and Parslow [1985]. T is temperature in degrees Celsius, and $I_{\mathrm{ECMWF}}(t)$ is the ECMWF monthly mean shortwave radiation, interpolated linearly to the day in question.

For zooplankton grazing we use a Holling type III function (see Fasham [1995], for a discussion of different grazing functions)

$$
G(\mathrm{P})=\frac{g \epsilon \mathrm{P}^{2}}{g+\epsilon \mathrm{P}^{2}}
$$

The individual biological parameters are listed in Table 2 , with the parameter values determined by a subjective optimization described in section 3.1.

While advection and diffusion of biological tracers is calculated with the time step of the physical model (a leapfrog time step of $2 \Delta t_{\text {phy }} \simeq 1$ hour), we used a simple Euler forward scheme with a time step of $\Delta t_{\mathrm{sms}} \simeq$ $15 \mathrm{~min}$ to integrate the source-minus-sink terms during each $2 \Delta t$ step of the physical model. 


\subsection{Advection Numerics}

In the standard GFDL MOM configuration, advection of temperature, salinity, and momentum is modeled using central differences both in space and in time. Among the main reasons for using central difference advection schemes are conceptual simplicity, little implicit diffusion, and $O\left(\Delta x^{2}\right)$ accuracy. A major drawback of central difference advection is, however, the generation of undershoots and overshoots when sharp tracer gradients are advected. Although this may usually be of little relevance in purely physical circulation models (but see Gerdes et al. [1991] and Farrow and Stevens [1995]), it becomes a severe problem in biogeochemical modeling. While tracer concentrations may change by orders of magnitude on a scale of very few grid points, the possible generation of negative concentrations is generally not acceptable as the assumptions on which the sourceminus-sink terms (10)-(13) are based will break down.

To ensure positive tracer concentrations, advection of ecosystem variables is often modeled by the positivedefinite upstream scheme. Among the advection schemes presently available (see Hecht et al. [1998] for a recent discussion) it is computationally cheapest, but it has the disadvantage of very large implicit diffusion, typically of at least the same order as explicit diffusion usually employed in ocean models (see section 3.2.1). Upstream differencing was, for example, used by Bacastow and Maier-Reimer [1991] (without additional explicit diffusion) and by Sarmiento et al. [1993] (with additional explicit diffusion). In the present study we ran one series of experiments using upstream differencing (in all three space dimensions) without explicit horizontal diffusion, but with explicit vertical diffusion including mixing by the mixed layer scheme. A second series of experiments was integrated using the less diffusive multidimensional positive definite central differences (MPDCD) scheme of Lafore et al. [1998]. It is based on the standard central difference equations but computes a flux limitation to satisfy a sufficient condition for positiveness (see the appendix). Note that the biharmonic horizontal diffusion operator, which in the present eddy-permitting model configuration is used to restrict the diffusion necessary for numerical reasons to very small scales, is not positive definite either. We have therefore rewritten the horizontal diffusion in flux form, which makes its inclusion into the MPDCD scheme straightforward. In this form the MPDCD scheme insures positiveness of the combined action of diffusion and advection.

Although the MPDCD scheme (with biharmonic horizontal diffusion) is about 4 times more expensive than simple upstream advection (without additional horizontal diffusion), it will be seen later that its less diffusive character has important and worthwhile consequences for the simulated biological production.

\section{Sensitivity Studies}

A number of experiments were performed to investigate the coupled model's sensitivity with respect to parameters of the biological equations and to the choice of both mixed layer scheme and advection numerics (Table 3 ). The physical model was initialized with a spunup state of a 24-year integration [Böning et al., 1996] of the original CME model. After inclusion of the additional surface levels and the respective TKE or KrausTurner scheme, the physical model was integrated for 1 year to adjust the upper ocean. The biology was inserted at the beginning of model year 26, to be integrated in the fully coupled mode with the evolving physical fields over a 3 -year period. The initial nitrate concentration field was taken from the climatological data of Conkright et al. [1994]. For the initial concentrations of $P, Z$, and $D$ we followed Sarmiento et al. [1993]; initial $P$ and $Z$ concentrations were set to $0.14 \mathrm{mmol} \mathrm{N} \mathrm{m}^{-3}$ and $0.014 \mathrm{mmol} \mathrm{N} \mathrm{m}^{-3}$ at the surface, respectively, decreasing exponentially with a scale depth of $100 \mathrm{~m}$. $D$ was initialized with a small value $\left(10^{-4} \mathrm{mmol} \mathrm{N} \mathrm{m}^{-3}\right)$ everywhere. No restoring was applied to the biological tracers at the closed boundaries. While a stable pattern of the simulated seasonal cycle is reached already after the first coupled year, all experiments discussed here were integrated over a 3-year period (model years 26 to 28), with results always being presented for the third year. An integration over 5 years was performed for two experiments and showed no significant changes in mean properities. Apart from some physically driven interannual fluctuations that appear naturally in our eddy-permitting model, this also holds for individual grid points. Exemplarily shown in Figure 2 is the temporal evolution of vertically integrated phytoplankton and zooplankton concentrations at three different stations as simulated by experiment $A$.

Each coupled 3-year experiment using TKE mixed layer dynamics and the MPDCD advection scheme takes about $180 \mathrm{CPU}$ hours on a Cray C90, and hence only a very limited number of individual fully coupled experiments could be performed.

Table 3. Individual Experiments

\begin{tabular}{ccc}
\hline Experiment & Mixed Layer Model & Advection Scheme \\
\hline A & TKE & MPDCD \\
B & TKE & upstream \\
C & $\mathrm{KT}+K_{\rho}=$ const. & MPDCD \\
D & KT $+K_{\rho} \sim N^{-1}$ & MPDCD \\
\hline
\end{tabular}

Biological parameters for all experiments are as in Table 2. Abbreviations are TKE, turbulent kinetic energy; MPDCD, multidimensional positive definite central differences; $\mathrm{KT}$, Kraus-Turner; $K_{\rho}$, vertical diffusivity; and $N$, Brunt-Väisälä frequency. 

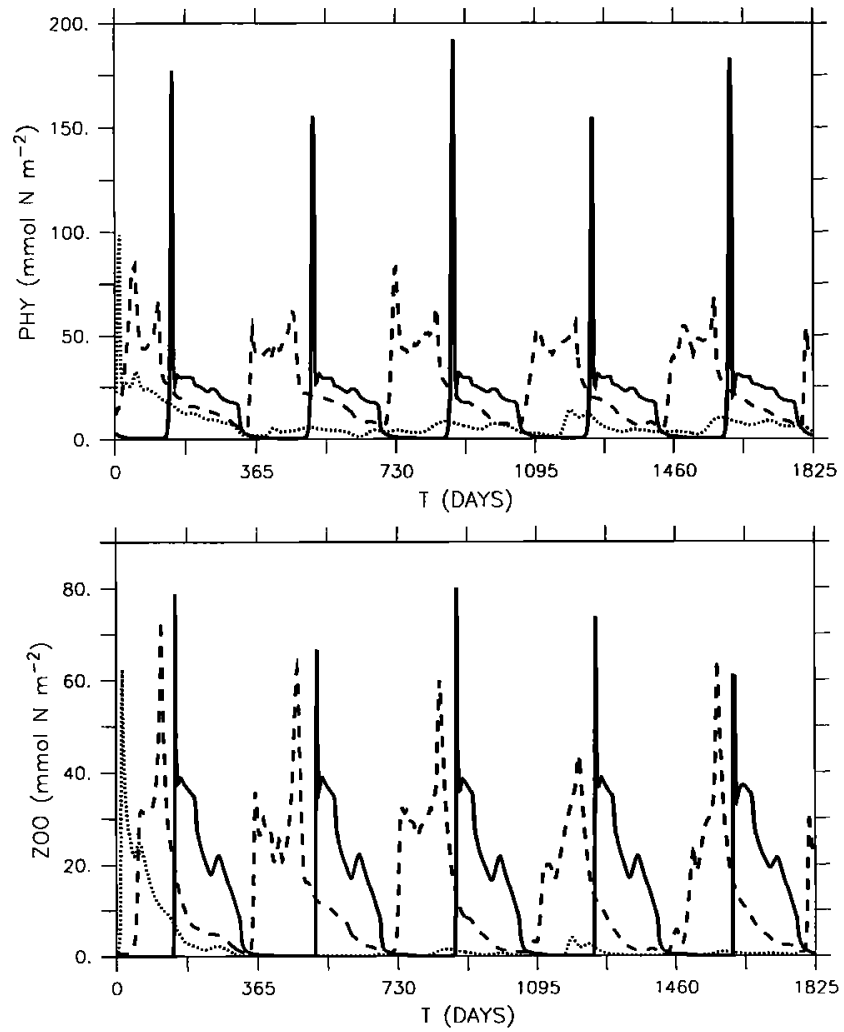

Figure 2. Five-year time series of vertically $(0-126 \mathrm{~m})$ integrated (top) phytoplankton and (bottom) zooplankton as simulated by experiment A (defined in Table 3 ) at ocean weather station (OWS) India (solid line), Bermuda Atlantic Time Series Study (BATS) (dashed line), and the oligotrophic site of the EUMELI program (dotted line). Units are $\mathrm{mmol} \mathrm{N} \mathrm{m}{ }^{-2}$. Coordinates of the stations are given in the text.

\subsection{Sensitivity With Respect to Biological Parameters}

An initial test experiment used ecosystem model parameters taken where possible from the literature, in particular, from Sarmiento et al. [1993] and Fasham [1995]. These were basically the values listed in Table 2, except for a smaller maximum grazing rate $(g=$ 1.0 day $\left.^{-1}\right)$, and different zooplankton mortality and excretion parameters $\left(\mu_{\mathrm{Z}}=0.05 \mathrm{mmol}^{-1} \mathrm{~m}^{3} \mathrm{~d}^{-1}\right.$, and $\gamma_{2}=0.15$ day $^{-1}$, respectively). Advection was modeled by the MPDCD scheme, and mixed layer physics were taken into account by the TKE model.

The main results of this first test were much too high values of primary production and chlorophyll concentration during the North Atlantic spring bloom. (For conversions from simulated nitrogen to carbon and chlorophyll we used fixed ratios of $\mathrm{C}: \mathrm{N}=6.625$ and $1.59 \mathrm{~g}$ chlorophyll per mol nitrogen, respectively.) For example, values as high as $260 \mathrm{mg} \mathrm{Cm}^{-3} \mathrm{~d}^{-1}$ and $16 \mathrm{mg}$ chlorophyll $\mathrm{m}^{-3}$ were reached at ocean weather station
(OWS) India $\left(59^{\circ} \mathrm{N}, 19^{\circ} \mathrm{W}\right)$. These initial values were more than 3 times higher than one would expect from observations [e.g., Fasham et al., 1993]. A further unrealistic feature was the too shallow nutricline, e.g., at about $z=50 \mathrm{~m}$ at the Bermuda Atlantic Time Series Study (BATS) $\left(32^{\circ} \mathrm{N}, 65^{\circ} \mathrm{W}\right)$, and too large nitrate concentrations in the mixed layer at the North Atlantic Bloom Experiment (NABE) site at $47^{\circ} \mathrm{N}, 20^{\circ} \mathrm{W}$ and OWS India after the (too intense) spring bloom, indicating an unrealistically efficient recycling of nutrients within the euphotic zone.

Further tuning of the biological parameters was done in a different but related environment by running onedimensional (1-D) biological models at the time series stations BATS and OWS India, at NABE and close to the French Joint Global Ocean Flux Study (JGOFS) oligotrophic site $\left(20^{\circ} \mathrm{N}, 30^{\circ} \mathrm{W}\right)$ of the eutrophic-mesotrophic-oligotrophic (EUMELI) program. These 1-D models used the physical environment (vertical diffusivity, temperature, vertical velocity) stored at the individual stations in 3 daily intervals during the initial 3-D test experiment. The much simplified 1-D setting, which neglects horizontal advection of biological tracer gradients, could reproduce the fully coupled 3D model results at NABE and OWS India rather well, while agreement was slightly poorer at EUMELI and considerably worse at BATS. By running 1-D biological models forced by 3-D physics at the four North Atlantic sites, CPU time requirements could be reduced by $O\left(10^{5}\right)$, thus allowing a large number of biological parameter sets to be tested.

The annual cycle simulated by the first 3-D test run could be improved at the four 1-D sites by decreasing excretion by zooplankton (decreasing $\mathrm{Z} \rightarrow \mathrm{N}$ ) and increasing zooplankton mortality (increasing $\mathrm{Z} \rightarrow \mathrm{D}$ ). Because spring bloom surface concentrations of phytoplankton and primary production were still too large (14 $\mathrm{mg} \mathrm{chl} \mathrm{m}^{-3}$ and $250 \mathrm{mg} \mathrm{C} \mathrm{m}^{-3} \mathrm{~d}^{-1}$, respectively, at OWS India), we finally increased the maximum grazing rate $g$. The parameter set found in this way by subjectively adjusting 1-D biological models forced by the 3-D physics at four sites in very different ecological regions is given in Table 2 and was used in all the subsequent 3-D experiments discussed herein. See Figure 2 for the 5-year time series of vertically integrated phytoplankton and zooplankton concentrations at the OWS India, BATS, and EUMELI stations as simulated by experiment $A$.

Clearly, we cannot claim to have carried out a complete exploration of the parameter space. Work is presently under way to objectively optimize the ecosystem model parameters via data assimilation methods. For the time being, our subjectively tuned model works sufficiently well to engage in the sensitivity studies reported below. A detailed analysis of the simulated 

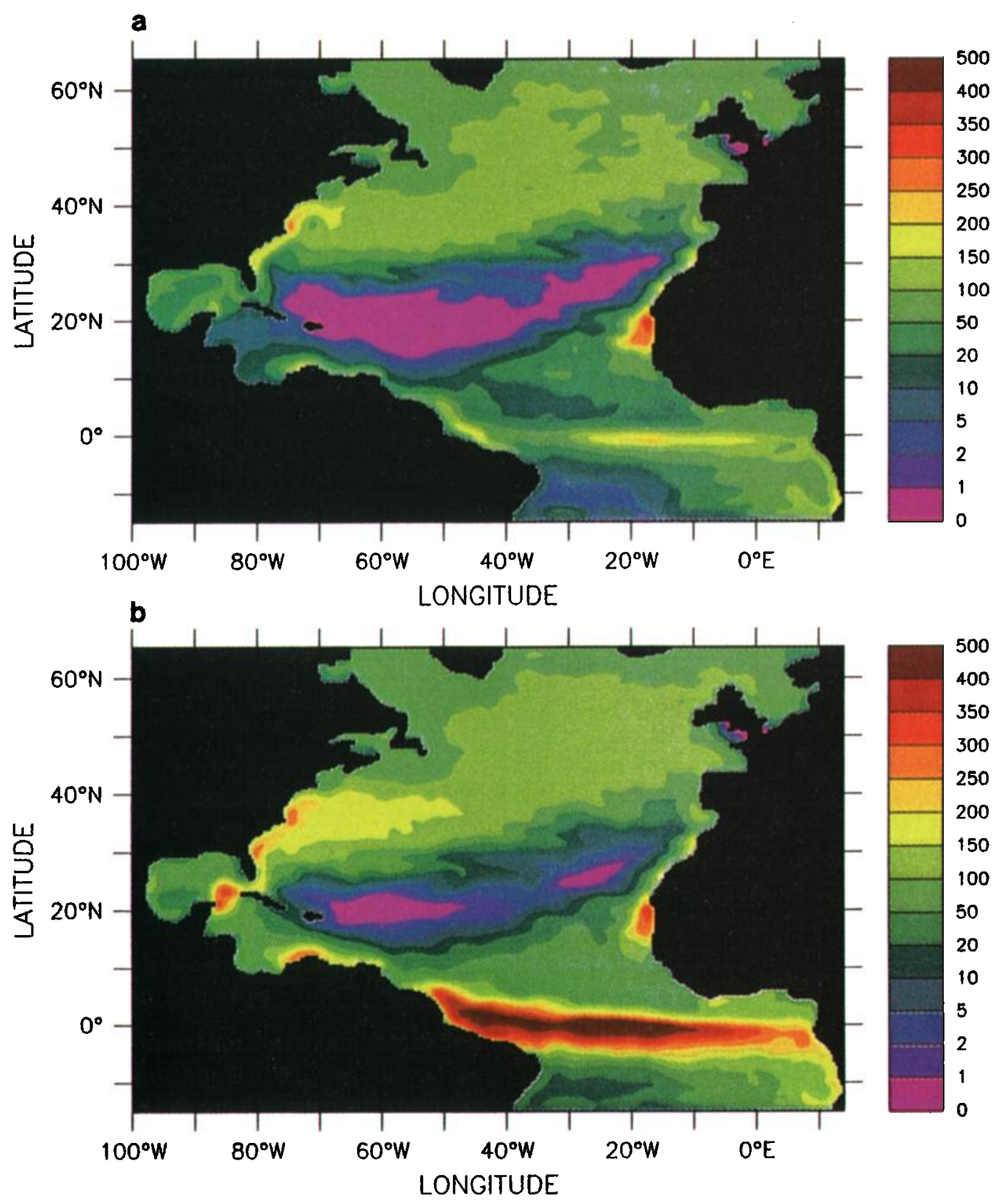

Plate 1. Annual primary production in $\mathrm{g} \mathrm{C}^{-2} \mathrm{yr}^{-1}$ for (top) experiment A employing the multidimensional positive definite central differences (MPDCD) advection scheme and (bottom) experiment $B$ using upstream advection.

ecosystem dynamics including the seasonal cycle at the four time series and process studies stations will be discussed in part 2 of this study (A. Oschlies et al., manuscript in preparation, 1998).

\subsection{Sensitivity With Respect to Different Numerical Advection Schemes}

Both the standard upstream advection as well as the MPDCD scheme are applied only to the advection of biological tracers, whereas temperature, salınity, and momentum are advected by the standard centraldifferences scheme of the MOM GFDL code [Pacanowsk et al., 1991]. Hence temperature, salinity, and velocity fields are identical for experiments $\mathrm{A}$ and $\mathrm{B}$, as are inıtial conditions, forcing, mixed layer dynamics, explicitly modeled diffusion, and biological parameters. The only difference lies in the numerical treatment of biological tracer advection by exactly the same flow field.

Shown in Plate 1 is the resulting annual primary production for the two experiments. The dominant feature is the much larger biological productıvity simulated by 
the upstream scheme along the equator, where the maximum increases from about $200 \mathrm{~g} \mathrm{C} \mathrm{m}^{-2} \mathrm{yr}^{-1}$ in experiment $\mathrm{A}$ to more than $400 \mathrm{~g} \mathrm{C} \mathrm{m}^{-2} \mathrm{yr}^{-1}$ when upstream advection is used. Primary production more than doubles in most places south of about $30^{\circ} \mathrm{N}$, with a more than threefold increase in the equatorial band between $8^{\circ} \mathrm{S}$ and $8^{\circ} \mathrm{N}$. As Table 4 shows, the enhanced primary production is fueled mainly by the extra nutrient input into the euphotic zone (here approximated by the upper $126 \mathrm{~m}$ ) by the vertical advection term. Whereas in experiment $\mathrm{A}$, advection and explicitly modeled vertical diffusion contribute about the same amount to the basin wide input of $\mathrm{NO}_{3}$ into the euphotic zone $(150 \mathrm{mmol}$ $\mathrm{m}^{-2} \mathrm{yr}^{-1}$ and $153 \mathrm{mmol} \mathrm{m}^{-2} \mathrm{yr}^{-1}$, respectively), changing to upstream advection significantly alters the nutrient fluxes: the advective vertical $\mathrm{NO}_{3}$ transport increases by more than $110 \%$ (i.e., by more than the contribution of the explicitly modeled diffusion), which is further accompanied by a $30 \%$ increase in the diffusive flux.

\subsubsection{Implicit diffusion of the upstream}

scheme. The dramatic increase in the advective nutrient transport into the euphotic zone that was observed for identical advecting velocity fields when switching from MPDCD to upstream numerics can be explained only by the much higher implicit diffusion of the upstream scheme. In fact, the additional vertical diffusion coefficient due to upstream differencing in comparison with central differencing of advection, which forms the base of the MPDCD scheme (see the appendix), is, to leading order, given by $K_{\text {num }}=|w| \Delta z / 2$ [e.g., Leonard, 1979]. Since $K_{\text {num }}$ depends linearly on the grid spacing $\Delta z$ we can expect that it is even greater in coarse-resolution models. For a given grid spacing $\Delta z$ the implicit diffusion of the upstream scheme is proportional to the advecting velocity. Differences in nutrient input and resulting primary production between upstream and MPDCD schemes are most pronounced in regions with large velocities, particularly along the equator, the Loop Current in the Gulf of Mexico, and the Gulf Stream. Implicit horizontal diffusivities of the upstream scheme can, in some places, reach $10^{8} \mathrm{~cm}^{2} \mathrm{~s}^{-1}$ and locally alter the biological tracer field. However, when averaged regionally (i.e., horizontally), these effects cancel except for diffusion through the region's boundaries. Consequently, it is primarily the extra vertical diffusion through the bottom of the euphotic zone that changes large-scale spatial averages of nitrate flux and associated biological production. When averaged over the entire closed basin, the flux into the upper $126 \mathrm{~m}$ is completely unaffected by horizontal processes (Table 4).

As an example, vertical diffusivities implicit in the upstream advection numerics as well as those computed explicitly by the TKE scheme are displayed along an instantaneous meridional section at $30^{\circ} \mathrm{W}$ in spring (Figure 3). In the upstream experiment the diffusion implicit in the upstream advection scheme (Figure 3, bottom) adds on top of the diffusivity explictly applied (Figure 3, top). In many places in and below the tropical and subtropical thermocline, the former is an order of magnitude larger than the explicitly applied diffusion. This is the case particularly in the equatorial upwelling region. Note that the tracer release experiment of Ledwell et al. [1993] carried out at about the same section around $25^{\circ} \mathrm{N}$ at a depth of about $300 \mathrm{~m}$ indicated vertical diffusivities slightly larger than $0.1 \mathrm{~cm}^{2} \mathrm{~s}^{-1}$, which is modeled well by the TKE scheme (Figure 3, top). At the same location the numerical diffusion implicit in the upstream scheme is alone already of the same order as the diffusion observed in the tracer release experiment. Of particular concern are the high implicit diffusivities of the upstream advection in the equatorial region: they are generally higher than $1 \mathrm{~cm}^{2} \mathrm{~s}^{-1}$, which contrasts with measured diffusivities smaller than $0.1 \mathrm{~cm}^{2} \mathrm{~s}^{-1}$ in the equatorial undercurrent (here at a depth of about $80 \mathrm{~m}$ ) and smaller than $1 \mathrm{~cm}^{2} \mathrm{~s}^{-1}$ below the undercurrent [e.g., Crawford, 1982], which again are relatively well simulated by the TKE scheme.

Table 4. Annual Primary Production (PP) and Nutrient Input Into the Upper $126 \mathrm{~m}$ of the Entire Basin and the Equatorial Region for Experiments A and B, Differing Only in the Advection Numerics

\begin{tabular}{lccccc}
\hline Experiment & Region & PP & NO $_{3}$ Input $_{126 m}$ \\
\cline { 3 - 6 } & & & Vertical Advection & Vertical Diffusion & $\begin{array}{c}\text { Horizontal } \\
\text { Advection+Diffusion }\end{array}$ \\
\hline A (MPDCD, TKE) & $15^{\circ} \mathrm{S}-65^{\circ} \mathrm{N}$ & 722 & 150 & 153 & 0 \\
B (upstream, TKE) & & 1284 & 315 & 199 & 0 \\
A (MPDCD, TKE) & $8^{\circ} \mathrm{S}-8^{\circ} \mathrm{N}$ & 800 & 457 & 56 & -148 \\
B (upstream, TKE) & & 2623 & 1005 & 102 & -100 \\
\hline
\end{tabular}

Units are $\mathrm{mmol} \mathrm{Nm}^{-2} \mathrm{yr}^{-1}$. 

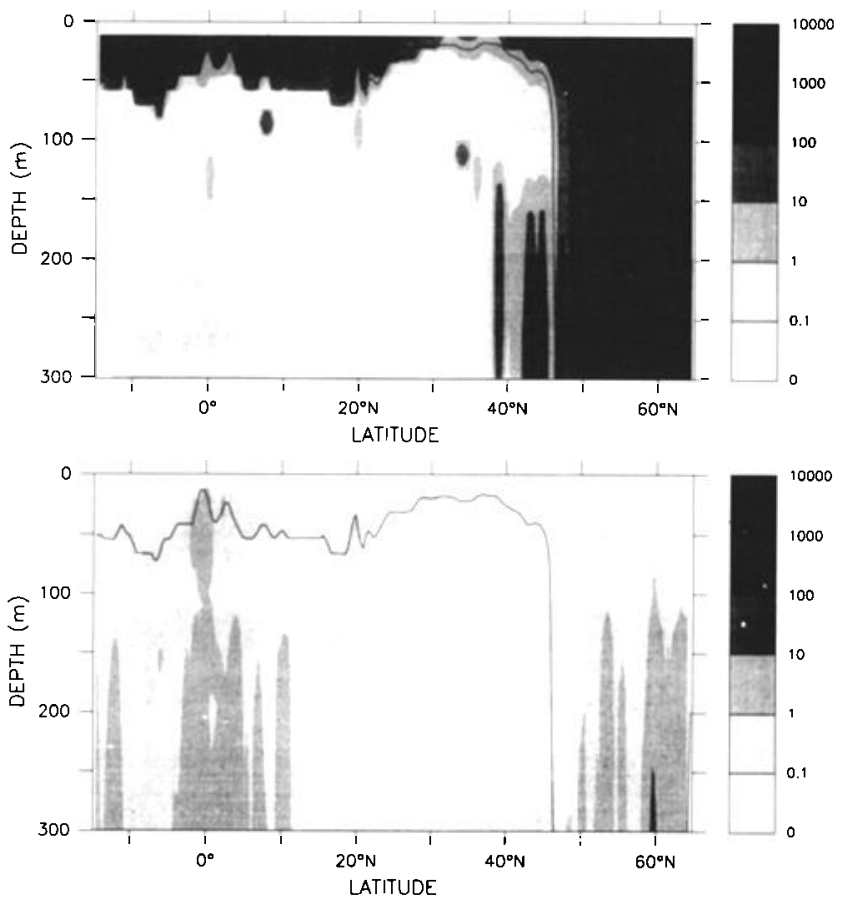

Figure 3. (top) Explicit vertical diffusivities as computed by the turbulent kinetic energy (TKE) model along a meridional section at $30^{\circ} \mathrm{W}$ in the upper $300 \mathrm{~m}$. Shown is an instantaneous section in May. (bottom) Numerical diffusivity, $|w| \Delta z / 2$, implicit in the upstream scheme along the same section. Units are square centimeters per second. The depth of the surface mixed layer defined by a density criterion $\left(\Delta \sigma=0.01 \mathrm{~kg} \mathrm{~m}^{-3}\right)$ is indicated by a solid line.

\subsubsection{Implicit diffusion of the MPDCD}

scheme. While the implicit diffusivity of the upstream advection is known, an analytical expression does not exist for the diffusivity implicit in the MPDCD numerics Here the flux limitation and hence the deviation from central difference advection will depend not only on the actual velocity but also on the actual tracer field. One can nevertheless get some impression of the effective numerical diffusion inherent in the MPDCD scheme by computing its effect on the basin-averaged variance of a conservative tracer. This tracer's spatial distribution should closely represent typical patterns of biological tracer concentrations in the coupled model.

To this extent we have taken a model state in late summer of the third year of experiment A. Mixed layers are shallow and vertical gradients in biological tracers are large. The biological interaction was then switched off, and the biological tracers, now strictly conservative, were advected for 3 months in separate experiments with either MPDCD, upstream, or central in time, central in space (CTCS) standard advection. Two series of experiments were performed, one without any explicit diffusion, the other with diffusion as present in exper-
Iments A and B. Figure 4 shows the evolution of the normalized variance of nitrate (Figure 4, top) and phytoplankton (Figure 4, bottom) computed over the entire basin. The tracer mean is conserved by all the schemes discussed, but only the standard CTCS advection conserves the variance of a passive tracer. Any decrease of the variance with time seen in the MPDCD and upstream runs with no explicit diffusion can be ascribed to implicit diffusion. While the MPDCD scheme leads to a reduction in the variance of nitrate by only two tenths of a promille, upstream advection reduces the variance by almost half a percent, i.e., by about 25 times the reduction observed with MPDCD numerics. The corresponding figures for phytoplankton are $9 \%$ reduction if MPDCD is used and 30\% reduction for upstream advection. (These values are much higher than found for
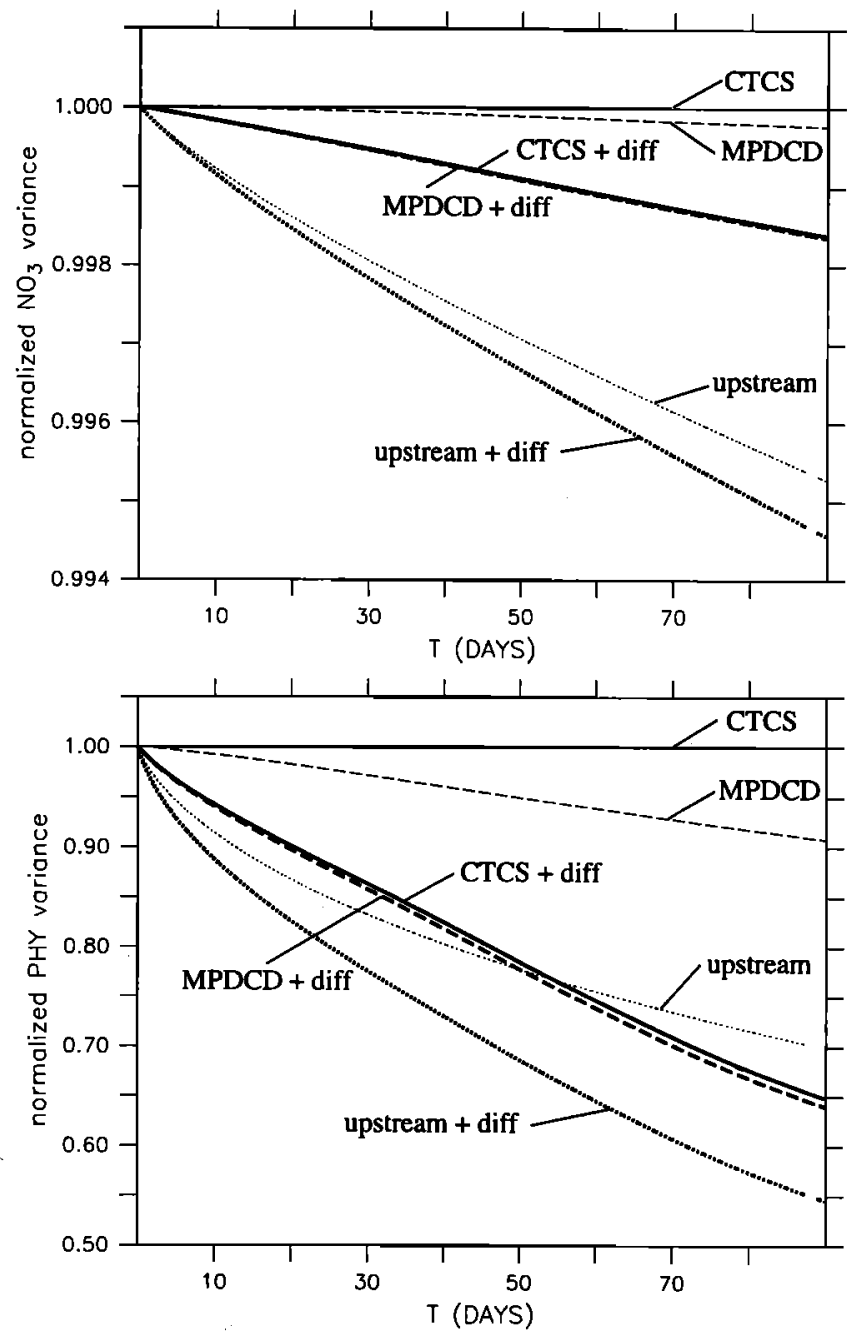

Figure 4. Temporal evolution of the normalized var1ance of (top) nitrate and (bottom) phytoplankton for different advection schemes and biological interaction terms switched off. For central in time, central in space (CTCS) advection without explicit diffusion the normalized variance remains exactly 1 . 
nitrate, reflecting the fact that the basin-averaged phytoplankton variance arises mainly from the upper ocean with large concentration gradients and high velocities, whereas the variance of the nitrate field is dominated by the quiet and more uniform ocean interior.)

Clearly, the MPDCD scheme preserves the variance of a tracer with a distribution typical for biological tracers much better than do upstream numerics. If we add explicit diffusion, the variance decreases also for the CTCS experiment. This decrease is not much altered when MPDCD advection plus explicit diffusion is used. Because explicit diffusion attenuates tracer gradients, its presence will tend to reduce the action of the MPDCD flux limiter, thereby reducing the amount of implicit diffusion. Note that again the decrease of the tracer variance is much more rapid in the upstream experiment. While both upstream and MPDCD scheme are positive definite, the CTCS scheme generates nonnegligible negative concentrations. In our test integration over only a 3 month period we found values as low as $-30 \mathrm{mmol} \mathrm{m}^{-3}\left(-8 \mathrm{mmol} \mathrm{m}^{-3}\right)$ for nitrate and $-0.9 \mathrm{mmol} \mathrm{m}^{-3}\left(-0.4 \mathrm{mmol} \mathrm{m}^{-3}\right)$ for phytoplankton without (with) explicit diffusion.

\subsubsection{Implications for equatorial nutrient}

trapping. In addition to the increase in vertically advected nitrate we already noted that the explicitly modeled diffusive $\mathrm{NO}_{3}$ input into the equatorial euphotic
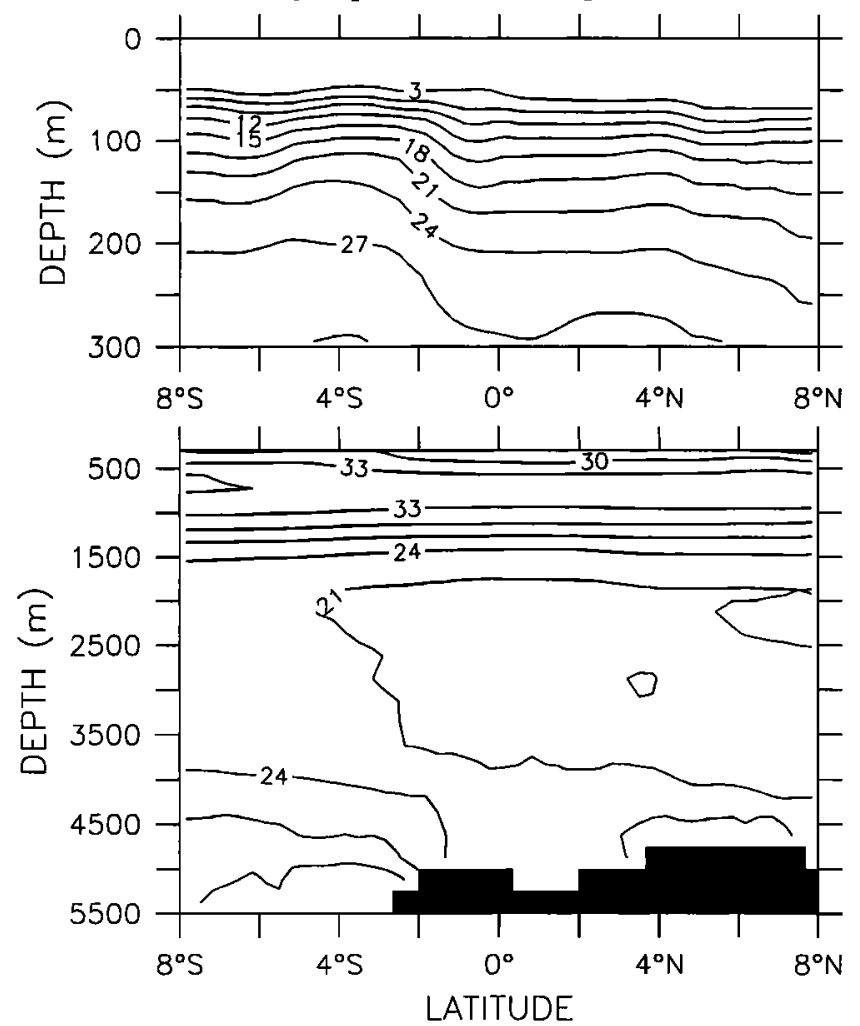

Figure 5a. Annual mean nitrate concentration in the upper equatorial Atlantic, zonally averaged over the band between $8^{\circ} \mathrm{S}$ and $8^{\circ} \mathrm{N}$ for (a) experiment A using MPDCD advection.

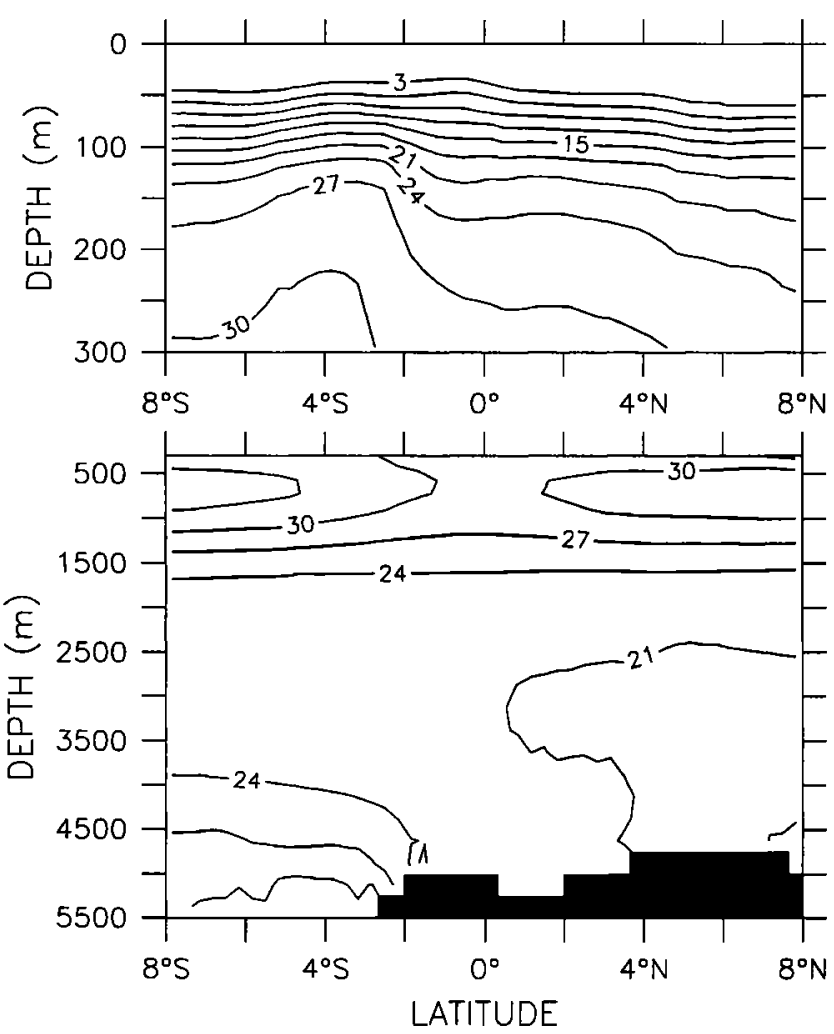

Figure 5b. Same as Figure 5a, but for experiment B with upstream numerics.

zone also increases on switching from MPDCD to upstream advection (Table 4). Since the explicitly applied vertical diffusivities computed by the TKE model are exactly the same in both model runs, this can only be explained by enhanced vertical tracer gradients in the upstream experiment. Shown in Figures $5 \mathrm{a}-5 \mathrm{c}$ is the zonally averaged nitrate field between $8^{\circ} \mathrm{S}$ and $8^{\circ} \mathrm{N}$. Equatorial nitrate concentrations right below the nutricline are systematically larger in the upstream experiment (Figure 5b, top, for the upper $300 \mathrm{~m}$ ) than in the corresponding MPDCD run (Figure 5a). Nitrate concentrations taken from the Conkright et al. [1994] atlas, which was used to initialize the model's nitrate field, are shown in Figure 5c. Obviously, both simulations lead to a an increase in the overall nitrate content in the upper $300 \mathrm{~m}$. With new primary production keeping down nitrate concentrations in the euphotic zone, this results in a sharpened nutricline.

What causes the elevated nutrient concentrations below the equatorial nutricline in the model experiments? A possible physical cause of overestimated nitrate fluxes into the surface layer of the equatorial Atlantic would be a too strong equatorial upwelling of subsurface water rich in nutrients. Such a reasoning was, for example, proposed by Sarmiento et al. [1993] to explain the much too high equatorial production in their coarse- 


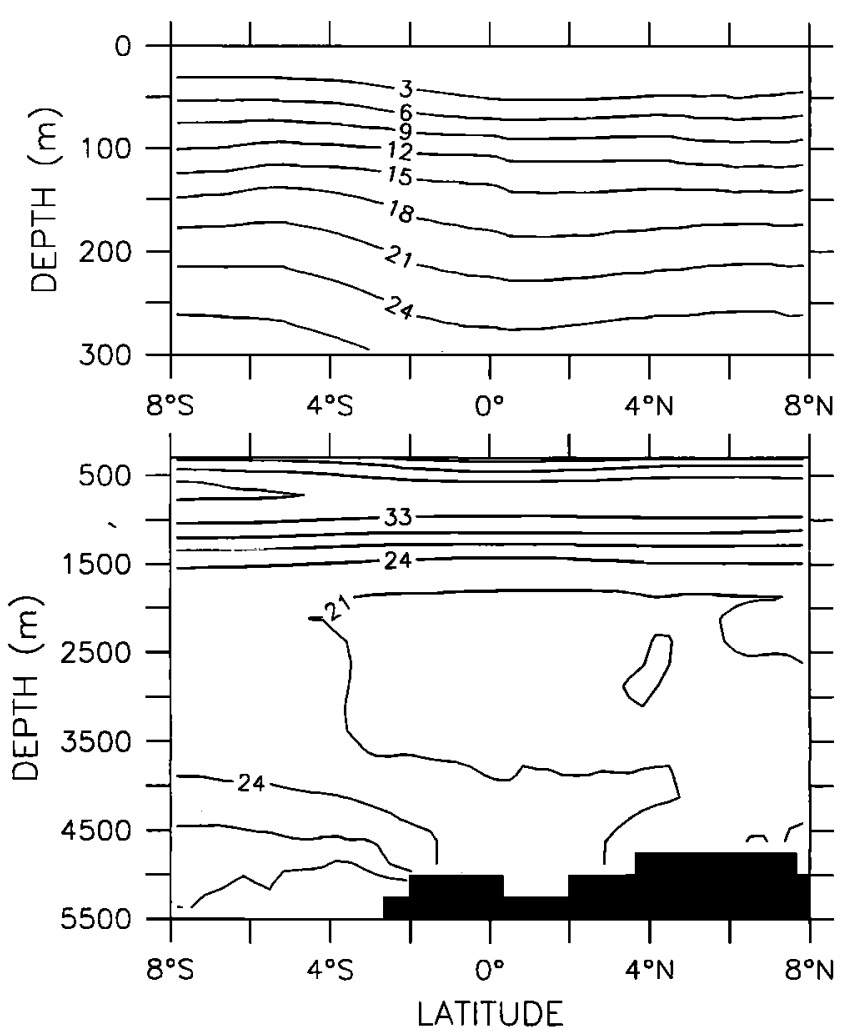

Figure 5c. Same as Figure 5a, but for climatological data of Conkright et al. [1994].

resolution model of the North Atlantic. The overturning volume-transport stream function of our coupled North Atlantic model, however, is the same for both upstream and MPDCD experiment and does not indicate substantial errors in the strength of the equatorial upwelling. Figure 6a displays the annual mean meridional overturning. Very similar to the results obtained by Blanke and Delecluse [1993], the equatorial upwelling between $2^{\circ} \mathrm{S}$ and $2^{\circ} \mathrm{N}$ amounts to slightly more than $16 \mathrm{~Sv}\left(1 \mathrm{~Sv}=10^{6} \mathrm{~m}^{3} \mathrm{~s}^{-1}\right)$ in the annual mean. This upwelling is fueled mainly by shallow recirculation cells centered a few degrees north and south of the equator. In the latitude range between $8^{\circ} \mathrm{S}$ and $8^{\circ} \mathrm{N}$, less than $4 \mathrm{~Sv}$ rise from depths greater than $300 \mathrm{~m}$. In his analysis of the $8^{\circ} \mathrm{S}$ and $8^{\circ} \mathrm{N}$ International Geophysical Year sections, Roemmich [1983] estimated a net upwelling of $6 \mathrm{~Sv}$ through the potential density surface $\sigma_{0}=26.2$ and of $10 \mathrm{~Sv}$ through $\sigma_{0}=25.5$. These isopycnal surfaces are indicated as dotted lines in Figure 6a. Obviously, our simulated annual mean upwelling agrees favorably with Roemmich's estimate. Confidence in the simulated equatorial upwelling is further strengthened by the magnitude of the simulated equatorial surface heat flux (Figure 7a). Agreement with observational heat flux climatologies like those of Esbensen and Kushnir [1981] (Figure $7 \mathrm{~b}$ ) is relatively close (within $\pm 50 \mathrm{~W} \mathrm{~m}^{-2}$ in the tropical and subtropical Atlantic) and considerably better than, for example, that reached by Sarmiento et al. [1993, Figure 19], who obtained equatorial heat fluxes exceeding those of the Esbensen and Kushnir [1981] climatology by more than $150 \mathrm{~W} \mathrm{~m}^{-2}$.

While the above analysis indicates that there are no substantial errors in the simulated meridional circulation in the tropical Atlantic, it is not entirely clear to what extent the closed southern boundary of the model affects the nutrient field in the equatorial Atlantic. A detailed inspection of the model's nitrate and velocity field reveals enhanced nitrate concentrations (enhanced by more than $5 \mathrm{mmol} \mathrm{NO}_{3} \mathrm{~m}^{-3}$ with respect to the initialization) near the South American coast at the southern boundary. Here the closed boundary enforces upwelling everywhere below a depth of $150 \mathrm{~m}$. A tongue of high nitrate concentrations develops that is centered in the depth range between 150 and $400 \mathrm{~m}$ and flows northward along the South American coast with the North Brazil Current. At the end of the 3-year integration, its northern limit reaches $8^{\circ} \mathrm{N}$ in both the MPDCD and

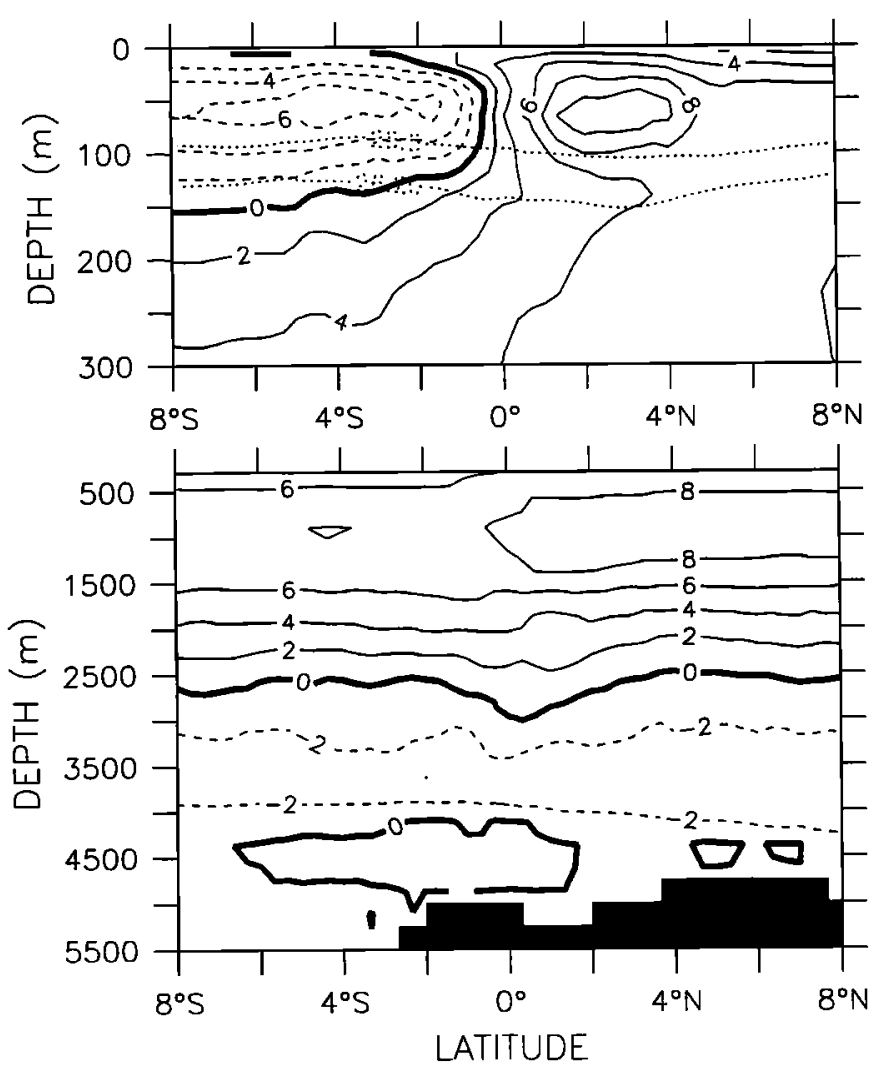

Figure 6a. Zonally and annually averaged meridional overturning stream function for experiments $\mathrm{A}$ and $\mathrm{B}$ (which have identical physics and differ only in the treatment of biological tracer advection). Units are sverdrups $\left(1 \mathrm{~Sv}=10^{6} \mathrm{~m}^{3} \mathrm{~s}^{-1}\right)$. Dotted lines refer to the potential density surfaces $\sigma_{0}=26.2$ and $\sigma_{0}=25.5$ (see text). 


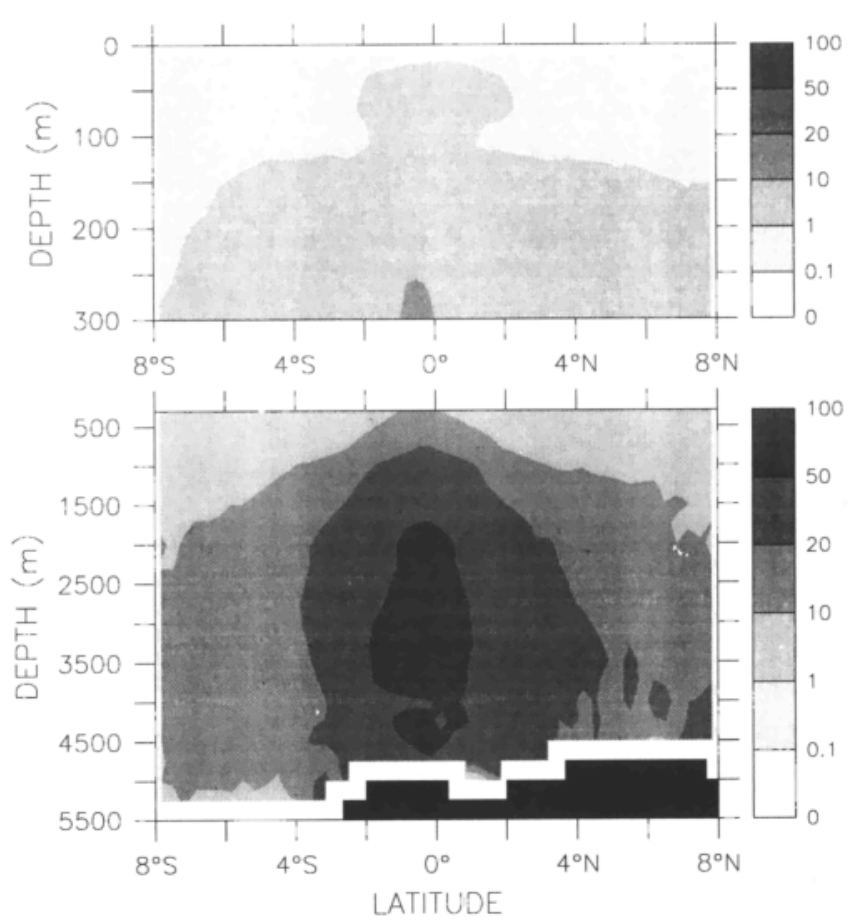

Figure 6b. Zonally and annually averaged vertical diffusion, $K_{\text {num }}$ implicit in the upstream advection scheme (in square centimeters per second).

the upstream experiment. Consequently, the presence of the southern boundary at $15^{\circ} \mathrm{S}$ is a likely cause of at least part of the increase of nitrate concentrations in the upper equatorial Atlantic seen in Figures $5 \mathrm{a}$ and $5 \mathrm{~b}$. Work beyond the approach taken here is needed (e.g., implementation of a restoring zone for biological variables or of open boundary conditions) to further clarify this issue.

Here we can only demonstrate the extent to which the implicit diffusion of the upstream advection scheme contributes to the observed increase in upper ocean nitrate concentrations (Figures 5a-5c). Corresponding to the meridional overturning stream function shown in Figure 6a, the zonally and annually averaged implicit diffusivity $K_{\text {num }}$ of the upstream scheme is plotted in Figure $6 \mathrm{~b} . K_{\text {num }}$ has a pronounced maximum at the equator even in the deep ocean where the overturning stream function does not indicate upwelling in the annual mean. Böning and Herrmann [1994] showed that seasonal variations in the near-surface meridional Ekman transport were associated with deep reaching seasonal overturning cells. Because $K_{\text {num }}=|w| \Delta z / 2$ is a nonlinear function of $w$, these seasonal variations show up in the annual mean implicit diffusivities.

Of particular relevance for the nitrate field is $K_{\text {num }}$ at the depth level of the Antarctic Intermediate Water (AAIW) that is marked by a distinct nitrate maximum centered at about $800 \mathrm{~m}$ (Figures 5a-5c). As Figure $6 \mathrm{~b}$ reveals, implicit vertical diffusivities of the upstream scheme exceed $10 \mathrm{~cm}^{2} \mathrm{~s}^{-1}$ at this depth. This is more than an order of magnitude larger than the diffusivities computed by the TKE model. Over the 3-year timescale of the coupled integration this corresponds to a diffusive vertical mixing scale of $300 \mathrm{~m}$ owing to upstream numerics, which is consistent with the observed erosion of the subsurface $\mathrm{NO}_{3}$ maximum of the AAIW at the equator (Figure $5 \mathrm{~b}$ ). Initial $\mathrm{NO}_{3}$ concentrations of $34.9 \mathrm{mmol} \mathrm{m}^{-3}$ at $800 \mathrm{~m}$ are reduced to $29.6 \mathrm{mmol} \mathrm{m}^{-3}$ after 3 years of upstream advection, whereas in the MPDCD experiment we still find $34.8 \mathrm{mmol} \mathrm{m}^{-3}$ Though we cannot assume that after a few years of integration the biological tracer field at $800 \mathrm{~m}$ is fully in equilibrium with the dynamics of the coupled model, it is noteworthy that corresponding equatorial nutrient concentrations change only slightly to $28.6 \mathrm{mmol} \mathrm{m}^{-3}$ and $34.6 \mathrm{mmol} \mathrm{m}^{-3}$ in the fifth year of upstream and MPDCD advection, respectively.

The high vertical diffusivity implicit in the upstream scheme obviously constitutes an unrealistical direct pathway for part of the AAIW's nitrate load into the upper equatorial Atlantic, where it can eventually help to

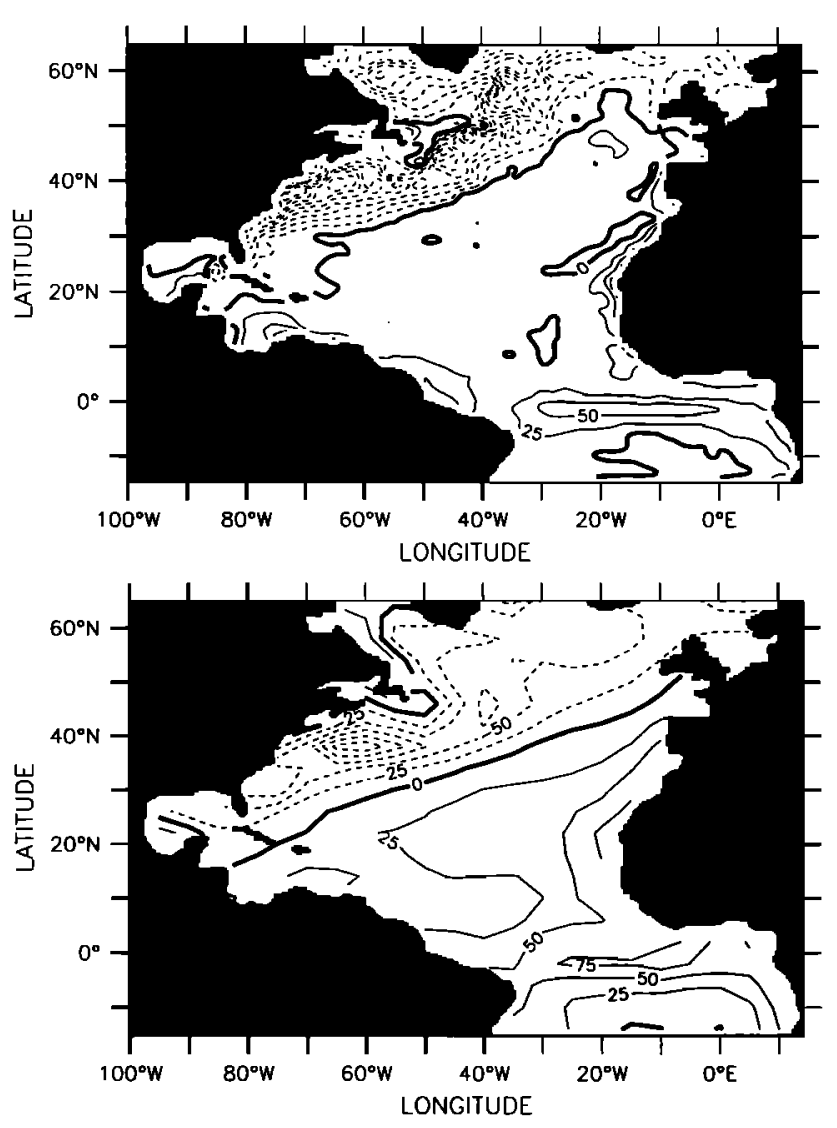

Figure 7. Annual mean surface heat flux (top) for experiment $A$ (and the identical physics experiment $B$ ) and (bottom) from observations analyzed by Esbensen and Kushnir [1981]. 
sustain enhanced levels of new and primary production. Interestingly, previous studies have also found unrealistically high nutrient concentrations below the equatorial nutricline. Najjar et al. [1992] referred to this problem as "nutrient trapping." Bacastow and MaierReimer [1991] reported high equatorial production and subsequent sinking and remineralization of detritus that led to the accumulation of nutrients and associated unrealistically low oxygen concentrations. Their model results could be improved by shifting from a particleonly ecosystem to a simulation that involved dissolved organic carbon (DOC) which could be exported from the equatorial region by the horizontally divergent flow field. The rather high average DOC concentrations of more than $150 \mathrm{mmol} \mathrm{C} \mathrm{m}^{-3}$ at the surface were in seemingly good accordance with the measurements of Sugimura and Suzuki [1988] which, however, have been subsequently withdrawn [Suzuki, 1993]. In the meantime, Matear and Holloway [1995] showed that by allowing only slight modifications to the circulation of Bacastow and Maier-Reimer's [1991] model, a simulation without DOC could well fit observations of new production and nutrients.

Our results indicate that changing from upstream advection to a less diffusive higher-order numerical scheme can significantly alleviate the often reported problem of too high equatorial new production and the associated trapping of nutrients. However, regarding the increase, albeit small, in equatorial nitrate concentrations observed in our experiment A (Figure 5a), we cannot claim that nutrient trapping is caused solely by inappropriate tracer advection numerics nor that DOC is unimportant. A more detailed discussion of this matter will require improvements to the southern boundary condition employed in our model of the North Atlantic. We further note that Najjar et al. [1992] employed the less diffusive central difference advection (though they had to cope with negative tracer concentrations), and, as in the upstream simulation of Bacastow and MaierReamer [1991], they also found that equatorial nutrient trapping could be efficiently reduced by separating export production into particular and dissolved organic material.

\subsection{Sensitivity to the Parameterization of Upper Ocean Turbulence}

From theoretical concepts [e.g., Sverdrup, 1953], field observations [e.g., Gardner et al., 1993], and modeling studies [e.g., Sarmiento et al., 1993] it is evident that a realistic description of the seasonal cycle of the depth of the surface mixed layer is essential for simulating biological production in the pelagic ocean. Both mixed layer schemes presented in section 2.1, the Kraus-Turner type bulk mixed layer and the TKE closure scheme, have tunable parameters that were subjectively adjusted to fit the climatological annual cycle of temperature at the four North Atlantic sites (BATS, NABE, OWS India, and EUMELI) as closely as possible (A. Oschlies et al, manuscript in preparation, 1998). Figure 8 (top) shows the winter mixed layer depth simulated by the TKE experiments (A and B) over the entire basin. It is defined here as the depth where potential density differs by $0.125 \mathrm{~kg} \mathrm{~m}^{-3}$ from the surface value, a criterion also used by Monterey and Levitus [1997] to construct upper ocean $(0-1000 \mathrm{~m})$ monthly mean mixed layer depth distributions from climatological data (Figure 8, bottom) (Using a sharper density criterion of $\sigma_{0}=0.01 \mathrm{~kg} \mathrm{~m}^{-3}$ to define the depth of the mixed layer would not be practical for climatologically averaged temperature and salinity observations. In the simulated synoptic model fields it would lead to slightly shallower mixed layers, without substantially changing the above picture ) The corresponding figures for runs $\mathrm{C}$ and $\mathrm{D}$ employing the Kraus-Turner (KT) model look very similar (not shown), though mixed layer depths are usually slightly deeper for the TKE scheme (typically by less than 10\%) This relatively small difference can be explained by the absence of penetrative convection in the present config-

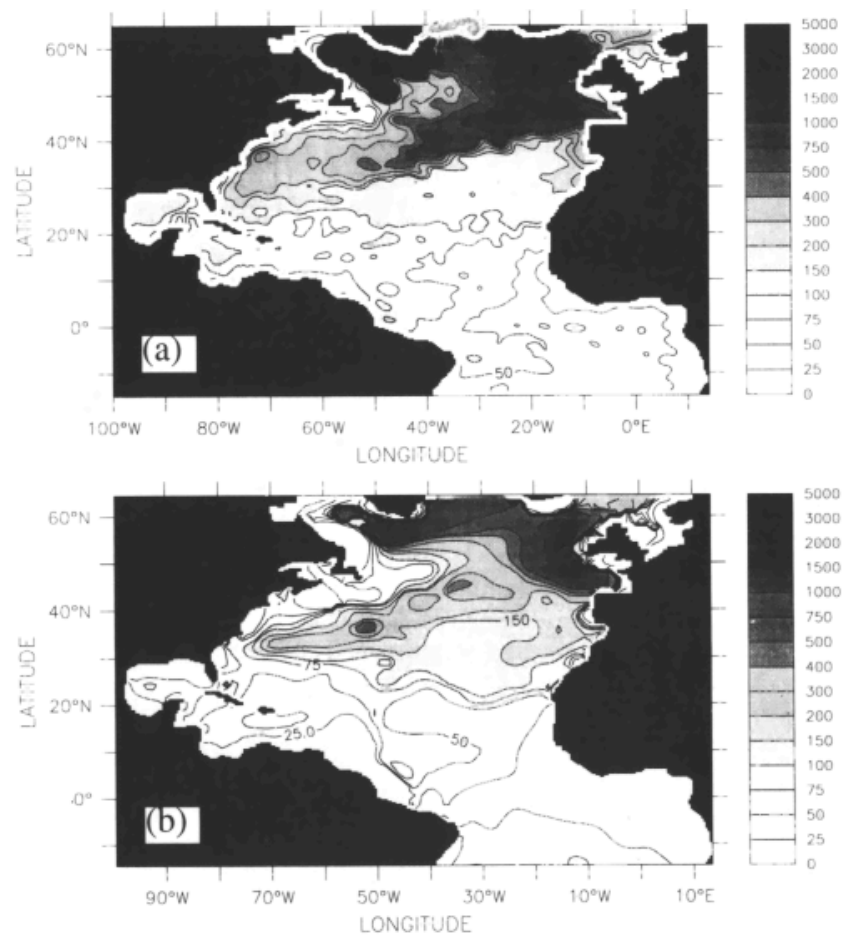

Figure 8. Depth of the mixed layer, defined by a density criterion $\left(\Delta \sigma=0.125 \mathrm{~kg} \mathrm{~m}^{-3}\right)$ showing (a) the situation as simulated by the TKE experiment $A$ (and the identical physics experiment $B$ ) at the beginning of March and (b) climatological observations [after Monterey and Levitus, 1997] for the upper $1000 \mathrm{~m}$ (that is, any mixed layers exceeding this depth range have been assigned the value $1000 \mathrm{~m}$ ). Units are meters 
uration of the $\mathrm{KT}$ mixed layer model, whereas in the TKE model there is turbulent transport of TKE, which leads to further erosion of the mixed layer inco the stably stratified thermocline [Käse, 1998]. There is a strikIng front in mixed layer depth crossing the northern part of the subtropical gyre. It separates mixed layers shallower than $150 \mathrm{~m}$ to the south and deeper than $500 \mathrm{~m}$ north of about $42^{\circ} \mathrm{N}$ in the eastern North Atlantic. This sharp meridional gradient in mixed layer depth is not very pronounced in the smoothed climatological data of Figure 8, bottom, but its signature has been observed in hydrographic sections [Paillet and Arhan, 1996]. However, mixed layer depths north of the front seem to be overestimated by the model; at the NABE site $\left(47^{\circ} \mathrm{N}\right.$, $20^{\circ} \mathrm{W}$ ), climatological mixed layers reach about $400 \mathrm{~m}$, whereas the modeled winter mixed layer extends down to depths greater than $700 \mathrm{~m}$ in all experiments performed in this study.

The overall pattern of the extratropical winter mixed layer at the end of the 24 year model spin-up already closely resembles that shown in Figure 8 . Because the model spin-up had been performed without any explicit mixed layer routine, it follows that if winter mixed layers are too deep in the eastern North Atlantic, these are not generated by either of the two mixed layer parameterizations used in this study. However, although previous modeling studies [e.g., Sterl and Kattenberg, 1994] indicate a quick adjustment of the upper ocean on a few-year timescale, we cannot completely rule out that a much longer integration with either mixed layer scheme switched on would not alleviate the problem. Work presently under way indeed indicates that spinning up the model without mixed layer routine and with surface fluxes formulated as a restoring condition (2) leads to a systematically larger net oceanic buoyancy loss compared to experiments with a mixed layer model included. This eventually results in slightly overstımated winter mixed layers in the subpolar North Atlantic. The differences we have found so far are so small that we have no reason to assume that our results presented here would be different were the model spun up with the mixed layer model included.

With the exception of the eastern North Atlantic and the sharp front crossing the northern part of the subtropical gyre, winter mixed layer depths of all model experiments A to D agree fairly well with climatological data. In summer this agreement holds almost everywhere. Absolute differences between the two mixed layer routines employed are generally smaller than $20 \mathrm{~m}$ in summer, though relative differences in the depth of the shallower summer mixed layers are now larger than in winter. Figure 9 shows the fields of the mixed layer depth at the beginning of September for run A using the TKE scheme (Figure 9a), for the Kraus-Turner experiment D with $K_{\rho} \sim N^{-1}$ below the mixed layer (Figure $9 b$ ) and for the observed climatology (Figure 9c)
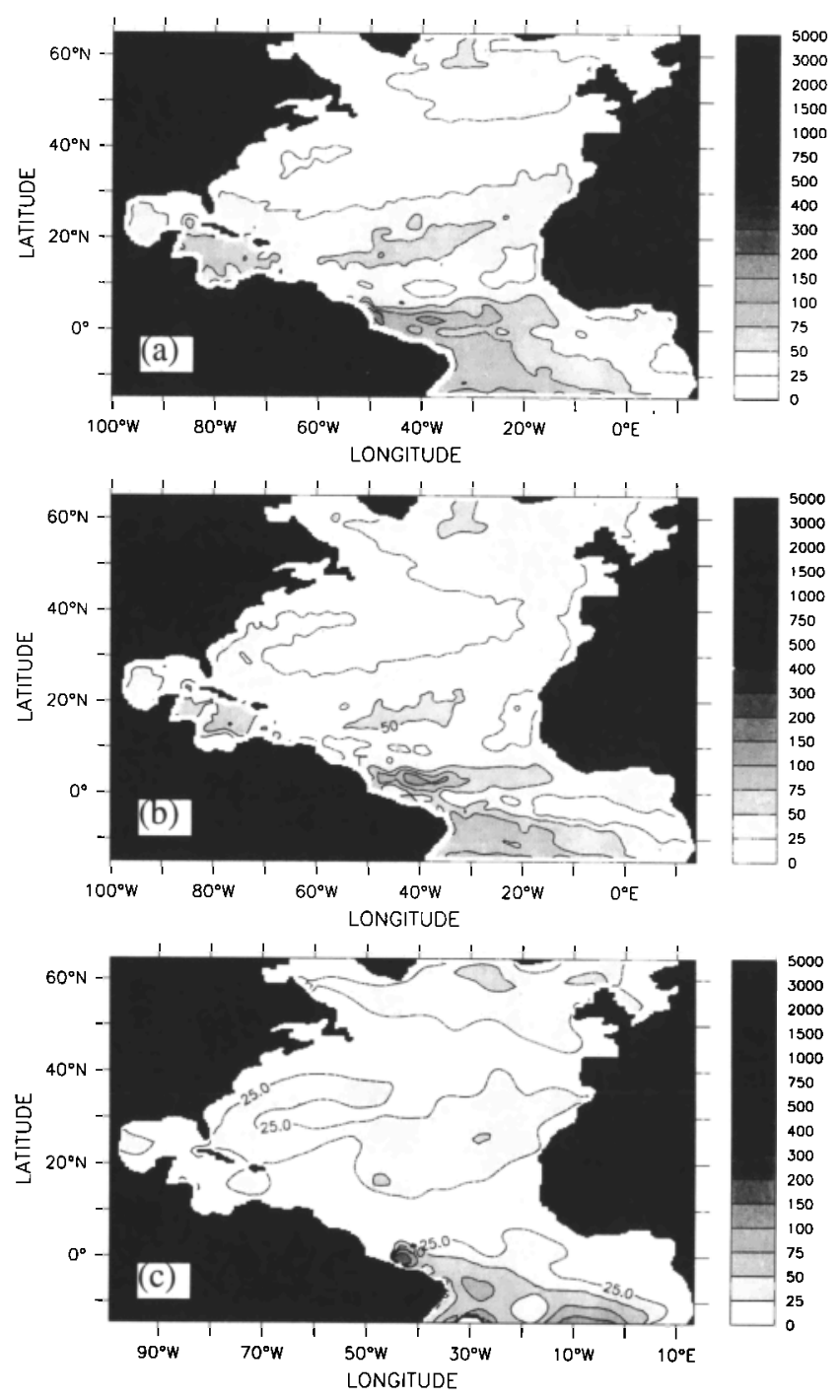

Figure 9. Depth of the mixed layer, defined by a density criterion $\left(\Delta \sigma=0.125 \mathrm{~kg} \mathrm{~m}^{-3}\right)$. Shown is the situation at the beginning of September as simulated by (a) run A using the TKE model, (b) by the KrausTurner experiment $\mathrm{D}$, and (c) for climatological data [after Monterey and Levitus, 1997]. Units are meters

Summer mixed layers for run C (with $K_{\rho}=0.3 \mathrm{~cm}^{2} \mathrm{~s}^{-1}$ ) are slightly shallower than those shown in Figure $9 \mathrm{~b}$.

3.3.1. The role of diapycnal diffusion. Despite the close agreement regarding the depth of the mixed layer, the results for primary production of the three experiments, A, C, and D, are surprisingly different. Plate 2 displays the annual primary production for the two experiments using Kraus-Turner mixed layer physics. The corresponding map for the TKE experiment is shown in Plate 1, top. While primary production rates vary by not more than about $10 \%$ between the three experiments in the subpolar and midlatitude North Atlantic (see also Table 5), differences are much larger in the subtropical gyre and the equatorial At- 

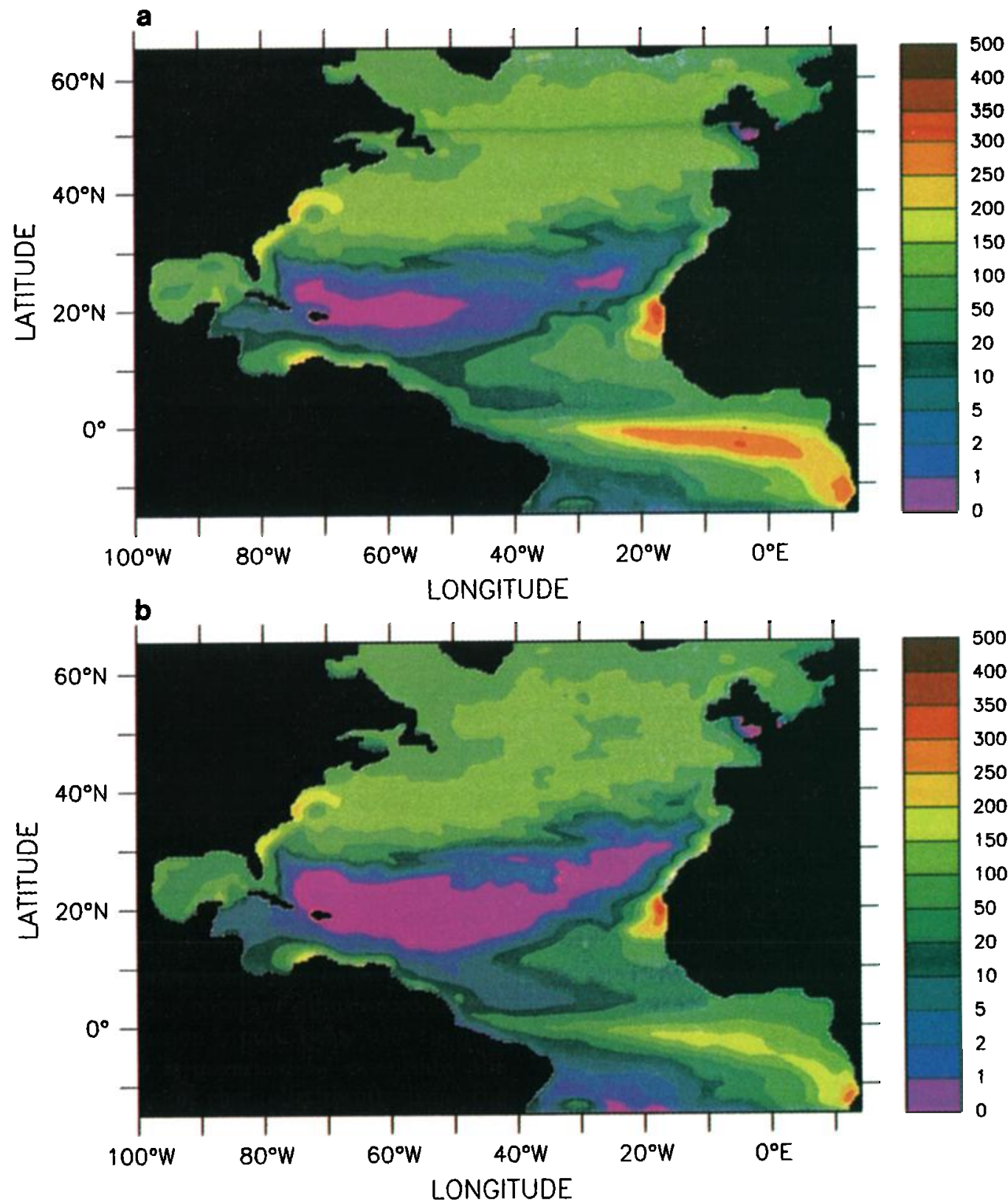

Plate 2. Annual primary production in $\mathrm{g} \mathrm{C} \mathrm{m}^{-2} \mathrm{yr}^{-1}$ for (top) experiment $\mathrm{C}$ employing the Kraus-Turner mixed layer model with a constant $K_{\rho}=0.3 \mathrm{~cm}^{2} \mathrm{~s}^{-1}$ in and below the thermocline and (bottom) experiment D using the same Kraus-Turner physics, but $K_{\rho} \sim N^{-1}$.

lantic. In the latter two regions the Kraus-Turner experiment $\mathrm{C}$ leads to a biological production almost twice as large as in run $\mathrm{D}$.

The only difference between runs $\mathrm{C}$ and $\mathrm{D}$ is the parameterization of vertical diffusion below the mixed layer. While run $\mathrm{C}$ uses a constant diffusion coefficient $K_{\rho}=0.3 \mathrm{~cm}^{2} \mathrm{~s}^{-1}$, diffusion in and below the thermocline in experiment $\mathrm{D}$ is governed by essentially the same $K_{\rho} \sim N^{-1}$ relation that also results from the TKE scheme (run A) In the main thermocline, diffu- sion coefficients of runs A and D are usually considerably smaller than the value of $0.3 \mathrm{~cm}^{2} \mathrm{~s}^{-1}$ employed in experiment $\mathrm{C}$ (see Figure 3a).

The reason for the apparent strong sensitivity of annual primary production to diapycnal diffusion in the tropical and subtropical thermocline can be understood by looking at the annual range of the depth of the nutricline. Figure 10 displays the depth of the $0.1 \mathrm{mmol} \mathrm{NO}_{3} \mathrm{~m}^{-3}$ surface which is taken as the upper limit of the nutricline The results shown are taken from 
Table 5. Annual Primary Production, Particle Export out of, and Nutrient Input Into the Upper $126 \mathrm{~m}$ of the Model for Different Regions

\begin{tabular}{|c|c|c|c|c|c|c|}
\hline Region & $\begin{array}{c}\text { Area, } \\
10^{12} \mathrm{~m}\end{array}$ & Experiment & $\mathrm{PP}$ & POM Export & $\mathrm{NO}_{3}$ Input & $\mathrm{NO}_{3}$ Input / PP \\
\hline $\begin{array}{l}\text { North Atlantic (NA), } \\
15^{\circ} \mathrm{S}-65^{\circ} \mathrm{N}\end{array}$ & 52 & $\begin{array}{l}\text { A } \\
\text { B } \\
\text { C } \\
\text { D }\end{array}$ & $\begin{array}{c}722 \\
1284 \\
914 \\
684\end{array}$ & $\begin{array}{l}275 \\
469 \\
328 \\
257\end{array}$ & $\begin{array}{l}303 \\
515 \\
359 \\
288\end{array}$ & $\begin{array}{c}0.42 \\
0.40 \\
0.39 \\
0.42\end{array}$ \\
\hline $\begin{array}{r}\text { Subpolar NA, } \\
50^{\circ}-65^{\circ} \mathrm{N}\end{array}$ & 6.4 & $\begin{array}{l}\text { A } \\
B \\
\text { C } \\
\text { D }\end{array}$ & $\begin{array}{l}1092 \\
1167 \\
1204 \\
1132\end{array}$ & $\begin{array}{l}375 \\
416 \\
397 \\
374\end{array}$ & $\begin{array}{l}391 \\
403 \\
423 \\
392\end{array}$ & $\begin{array}{c}0.36 \\
0.35 \\
0.35 \\
0.35\end{array}$ \\
\hline $\begin{array}{c}\text { Midlatitide NA } \\
30^{\circ}-50^{\circ} \mathrm{N}\end{array}$ & 12.5 & $\begin{array}{l}\text { A } \\
\text { B } \\
\text { C } \\
\text { D }\end{array}$ & $\begin{array}{l}1145 \\
1337 \\
1204 \\
1071\end{array}$ & $\begin{array}{l}479 \\
555 \\
477 \\
433\end{array}$ & $\begin{array}{l}482 \\
598 \\
485 \\
443\end{array}$ & $\begin{array}{c}0.42 \\
0.45 \\
0.40 \\
0.41\end{array}$ \\
\hline $\begin{array}{l}\text { Subtropical Gyre, } \\
12^{\circ}-30^{\circ} \mathrm{N}, 70^{\circ}-22^{\circ} \mathrm{W}\end{array}$ & 8.2 & $\begin{array}{l}A \\
B \\
C \\
D\end{array}$ & $\begin{array}{c}66 \\
186 \\
101 \\
52\end{array}$ & $\begin{array}{l}20 \\
62 \\
35 \\
17\end{array}$ & $\begin{array}{l}21 \\
72 \\
32 \\
26\end{array}$ & $\begin{array}{c}0.32 \\
0.39 \\
0.32 \\
0.50\end{array}$ \\
\hline $\begin{array}{l}\text { Canary Basin, } \\
8^{\circ}-30^{\circ} \mathrm{N}, 22^{\circ} \mathrm{W} \text {-coast }\end{array}$ & 1.8 & $\begin{array}{l}\text { A } \\
\text { B } \\
\text { C } \\
\text { D }\end{array}$ & $\begin{array}{l}1193 \\
1294 \\
1360 \\
1116\end{array}$ & $\begin{array}{l}403 \\
455 \\
457 \\
377\end{array}$ & $\begin{array}{l}430 \\
499 \\
497 \\
422\end{array}$ & $\begin{array}{c}0.36 \\
0.39 \\
0.37 \\
0.38\end{array}$ \\
\hline $\begin{array}{l}\text { Equatorial Atlantic, } \\
8^{\circ} \mathrm{S}-8^{\circ} \mathrm{N}\end{array}$ & 10.5 & $\begin{array}{l}\text { A } \\
\text { B } \\
\text { C } \\
\text { D }\end{array}$ & $\begin{array}{c}800 \\
2623 \\
1331 \\
711\end{array}$ & $\begin{array}{l}292 \\
895 \\
446 \\
267\end{array}$ & $\begin{array}{c}365 \\
1008 \\
525 \\
290\end{array}$ & $\begin{array}{l}0.45 \\
0.38 \\
0.39 \\
0.41\end{array}$ \\
\hline $\begin{array}{l}\text { Gulf of Mexico, } \\
18^{\circ}-32^{\circ} \mathrm{N}, 100^{\circ}-82^{\circ} \mathrm{W}\end{array}$ & 1.9 & $\begin{array}{l}A \\
B \\
C \\
D\end{array}$ & $\begin{array}{c}695 \\
1218 \\
790 \\
624\end{array}$ & $\begin{array}{l}314 \\
550 \\
340 \\
280\end{array}$ & $\begin{array}{l}266 \\
528 \\
319 \\
266\end{array}$ & $\begin{array}{l}0.38 \\
0.43 \\
0.40 \\
0.43\end{array}$ \\
\hline
\end{tabular}

Units are mmol N m${ }^{-2} \mathrm{yr}^{-1}$. The ratio of nitrate input to primary production can be viewed as proxy for the model's $f$ ratio.

experiment $\mathrm{A}$ but are not much different for runs $\mathrm{C}$ and $\mathrm{D}$, though in run $\mathrm{C}$ the $0.1 \mathrm{mmol} \mathrm{NO}_{3} \mathrm{~m}^{-3}$ surface outcrops just south of the equator in the eastern basin. Shown in Figure 10a is the situation in early March, when $\mathrm{NO}_{3}$ concentrations exceed $0.1 \mathrm{mmol} \mathrm{m}^{-3}$ almost everywhere in the deep winter mixed layers north of about $30^{\circ} \mathrm{N}$ and a depth level with $\mathrm{NO}_{3}$ concentrations as low as $0.1 \mathrm{mmol} \mathrm{NO}_{3} \mathrm{~m}^{-3}$ does not exist in the water column. Wherever a $0.1 \mathrm{mmol} \mathrm{NO} \mathrm{N}_{3} \mathrm{~m}^{-3}$ surface exists, it will generally lie below the base of the mixed layer (Figure 8 ) because a nutricline cannot persist within the mixed layer. In summer this surface exists almost everywhere (Figure 10b). Except for the northern half of the subpolar gyre and some coastal and equatorial upwelling regions, the overlying mixed layer of the ocean is essentially depleted of nutrients.

From Figure 10 it is evident that in the tropics and subtropics the nutricline is usually well below the base of the mixed layer in summer as in winter. While nutri- ents will be entrained into the deep winter mixed layers in higher latitudes, here only advection and diapycnal diffusion can generate an input of nutrients into the euphotic zone. With vertical advection being directed downward (Ekman pumping) over the subtropical gyre, vertical diffusion becomes increasingly important.

The individual contributions of vertical advection, vertical diffusion, and entrainment by the Kraus-Turner mixed layer (only for experiments $\mathrm{C}$ and $\mathrm{D}$ ) are given in Table 6. For the TKE experiment, vertical diffusion and entrainment into the surface mixed layer are not treated separately, and only the combined effect is indicated. It is evident that the strong seasonal cycle in the depth of the mixed layer dominates the input of nitrate into the euphotic zone in the subpolar and midlatitude North Atlantic. In these regions the contribution due to Kraus-Turner mixing is much larger than that of vertical advection and diffusion. Changes in vertical diffusivities have a significant effect only in the 


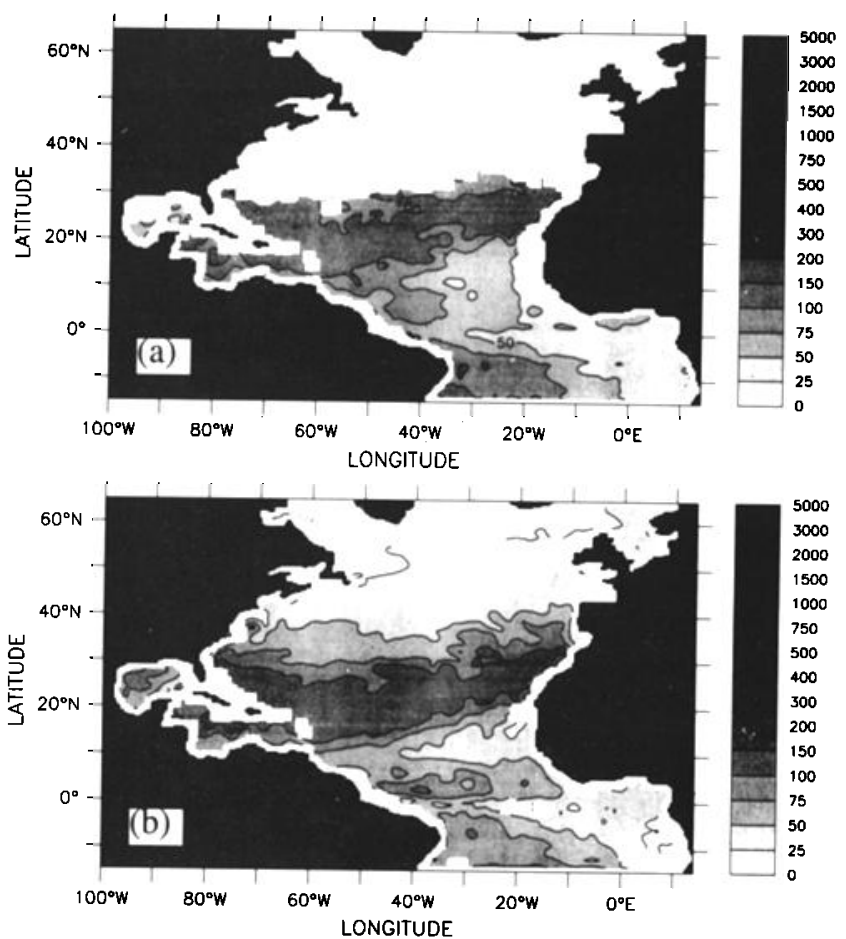

Figure 10. Depth of the $0.1 \mathrm{mmol} \mathrm{NO}_{3} \mathrm{~m}^{-3}$ surface (a) at the beginning of March and (b) in early September. Results shown are for run A, but apart from the equatorial Atlantic the picture would look almost identical for experiments $\mathrm{C}$ and $\mathrm{D}$. Units are meters.

tropics and subtropics, where the seasonally deepening mixed layer in general does not reach the nutricline and consequently cannot entrain nitrate.

3.3.2. The role of viscous dissipation. In most places in the ocean, geostrophy is the dominant balance of forces. On scales larger than the Rossby radius of deformation the flow will then adjust geostrophically to a given density field. While vertical diffusion may well alter the density and therefore the flow field, one may expect that vertical viscosity is not a very influential model parameter. The above statement, however, does not hold in places where ageostrophic effects are domlnant. This will be the case close to boundaries and at the equator.

In their analysis of the momentum balance of the Atlantic Equatorial Undercurrent (EUC), Wacongne [1989] and Blanke and Delecluse [1993] showed that friction exerts a major control on the strength of the EUC and its penetration into the eastern basin. While the TKE model computes viscosities as a function of vertical shear and static stability, viscosity is set to a constant value of $K_{m}=10 \mathrm{~cm}^{2} \mathrm{~s}^{-1}$ in experiments $\mathrm{C}$ and $\mathrm{D}$ using the Kraus-Turner model. The latter value is a typical choice for viscosity in ocean circulation models [e.g., Böning et al., 1996]. Shown in Figure 11 is the annual mean of the zonal velocity at the equator, for experiment A employing the TKE scheme (Figure 11a) and for experiment D using a constant coefficient of viscosity below the Kraus-Turner mixed layer (Figure 11b). Clearly, the EUC is considerably stronger and penetrates much farther into the eastern basin when TKE physics is used. As Blanke and Delecluse [1993] showed, this can be explained by the very low viscosity $\left(<0.1 \mathrm{~cm}^{2} \mathrm{~s}^{-1}\right)$ in the core of the EUC where velocity shear is at its minimum. The extent to which viscosity contributes to this difference is illustrated in Figure 11c. It shows the results of a test experiment where we have used the same TKE parameterization as in run $\mathrm{A}$, but this time we imposed a lower

Table 6. Annual Primary Production and Nutrient Input Into the Upper $126 \mathrm{~m}$ for Experiments A, C, and D Averaged Over Different Regions

\begin{tabular}{|c|c|c|c|c|c|}
\hline \multirow[t]{2}{*}{ Experiment } & \multirow[t]{2}{*}{ Region } & \multirow[t]{2}{*}{$\mathrm{PP}$} & \multicolumn{3}{|c|}{$\mathrm{NO}_{3}$ Input $_{126 \mathrm{~m}}$} \\
\hline & & & Vertical Diffusion & KT Entrainment & Vertical Advection \\
\hline A (MPDCD, TKE) & $50^{\circ}-65^{\circ} \mathrm{N}$ & 1092 & 296 & & 98 \\
\hline $\mathrm{C}$ (MPDCD, KT $+K_{\rho}=$ const. $)$ & & 1204 & 22 & 302 & 75 \\
\hline $\mathrm{D}\left(\mathrm{MPDCD}, \mathrm{KT}+K_{\rho} \sim N^{-1}\right)$ & & 1132 & 14 & 279 & 71 \\
\hline A (MPDCD, TKE) & $30^{\circ}-50^{\circ} \mathrm{N}$ & 1145 & 402 & & 27 \\
\hline $\mathrm{C}$ (MPDCD, KT $+K_{\rho}=$ const.) & & 1204 & 49 & 337 & 39 \\
\hline $\mathrm{D}\left(\mathrm{MPDCD}, \mathrm{KT}+K_{\rho} \sim N^{-1}\right)$ & & 1071 & 19 & 332 & 39 \\
\hline A (MPDCD, TKE) & $12^{\circ}-30^{\circ} \mathrm{N}$ & 66 & 13 & .. & -40 \\
\hline $\mathrm{C}$ (MPDCD, KT $+K_{\rho}=$ const.) & $70^{\circ}-22^{\circ} \mathrm{W}$ & 101 & 46 & 4 & -34 \\
\hline $\mathrm{D}\left(\mathrm{MPDCD}, \mathrm{KT}+K_{\rho} \sim N^{-1}\right)$ & & 52 & 10 & 2 & -31 \\
\hline A (MPDCD, TKE) & $8^{\circ} \mathrm{S}-8^{\circ} \mathrm{N}$ & 800 & 56 & .. & 457 \\
\hline $\mathrm{C}$ (MPDCD, $\mathrm{KT}+K_{\rho}=$ const.) & & 1331 & 110 & 3 & 524 \\
\hline $\mathrm{D}\left(\mathrm{MPDCD}, \mathrm{KT}+K K_{\rho} \sim N^{-1}\right)$ & & 711 & 18 & 2 & 424 \\
\hline
\end{tabular}

Units are $\mathrm{mmol} \mathrm{N} \mathrm{m}^{-2} \mathrm{yr}^{-1}$ 


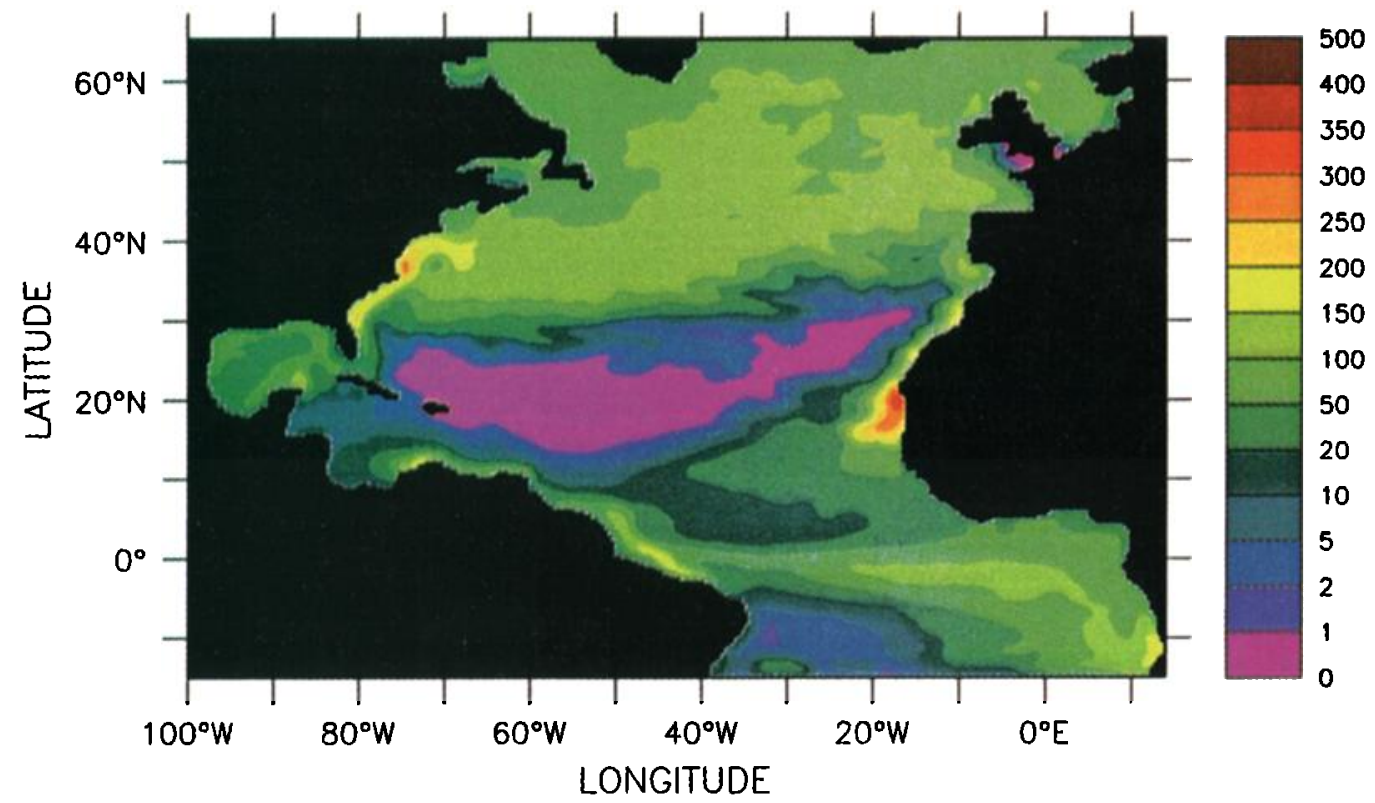

Plate 3. Annual primary production in $\mathrm{g} \mathrm{C} \mathrm{m}^{-2} \mathrm{yr}^{-1}$ for the test experiment using TKE physics, but imposing a lower limit of $K_{m}=10 \mathrm{~cm}^{2} \mathrm{~s}^{-1}$ to the viscosity.
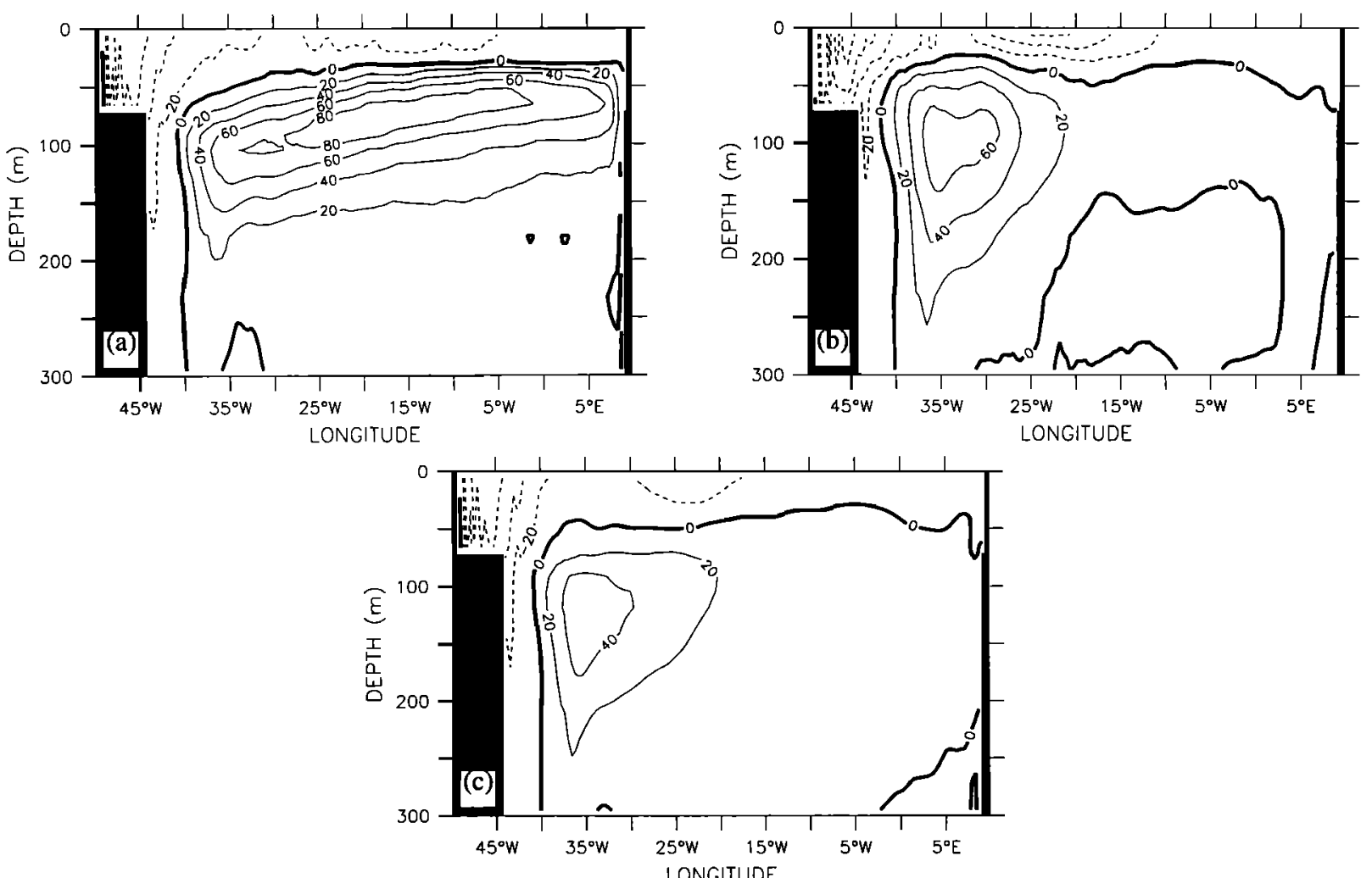

Figure 11. Annual mean zonal velocity along the equator (average between $1^{\circ} \mathrm{S}$ and $0^{\circ}$ ) for (a) experiment A with TKE physics, (b) the Kraus-Turner experiment D with constant viscosity below the mixed layer, and (c) TKE physics with viscosity set to $K_{m} \geq 10 \mathrm{~cm}^{2} \mathrm{~s}^{-1}$. Units are centimeters per second.

limit of $K_{m}=10 \mathrm{~cm}^{2} \mathrm{~s}^{-1}$ to the viscosity. No changes have been made to the parameterization of diapycnal diffusion. It is evident that the increased viscosity leads to a much more rapid dissipation of the EUC along its way eastward In fact, the resulting zonal velocity field closely resembles that of experiment D using the same high viscosity below the Kraus-Turner mixed layer (Fig- ure $11 \mathrm{~b})$.

The farther eastward penetration of the EUC in TKE experiment $A$ agrees well with observations taken during the FOCAL campaign [e.g., Verstraete, 1992] at $4^{\circ} \mathrm{W}$ mean eastward velocities measured by the profiling current method (PCM) in the EUC were found 

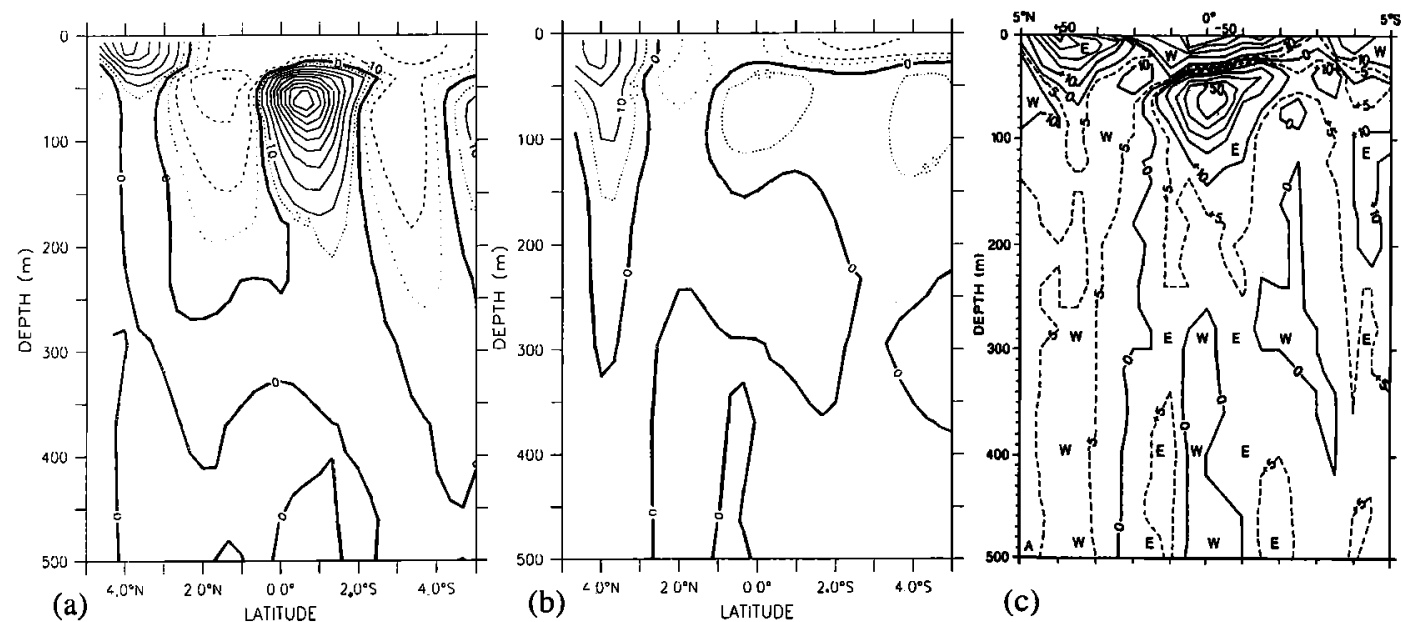

Figure 12. Mean zonal velocity at $4^{\circ} \mathrm{W}$ for (a) experiment $\mathrm{A}$ with TKE physics, (b) the KrausTurner experiment D with constant viscosity below the mixed layer, and (c) profiling current method observations during the FOCAL campaign [Verstraete, 1992]. Units are centimeters per second.

to exceed $50 \mathrm{~cm} \mathrm{~s}^{-1}$ (Figure 12c). Mean zonal velocities at $4^{\circ} \mathrm{W}$ as simulated by experiments $\mathrm{A}$ and $\mathrm{D}$ are shown in Figures 12a and 12b, respectively. In the annual mean the core of the EUC is at a depth of about
$60 \mathrm{~m}$ both in the observations and in the TKE experiment A, though simulated maximum velocities of about $90 \mathrm{~cm} \mathrm{~s}^{-1}$ are considerably higher than those observed, some of which may be explained by the PCM mea-
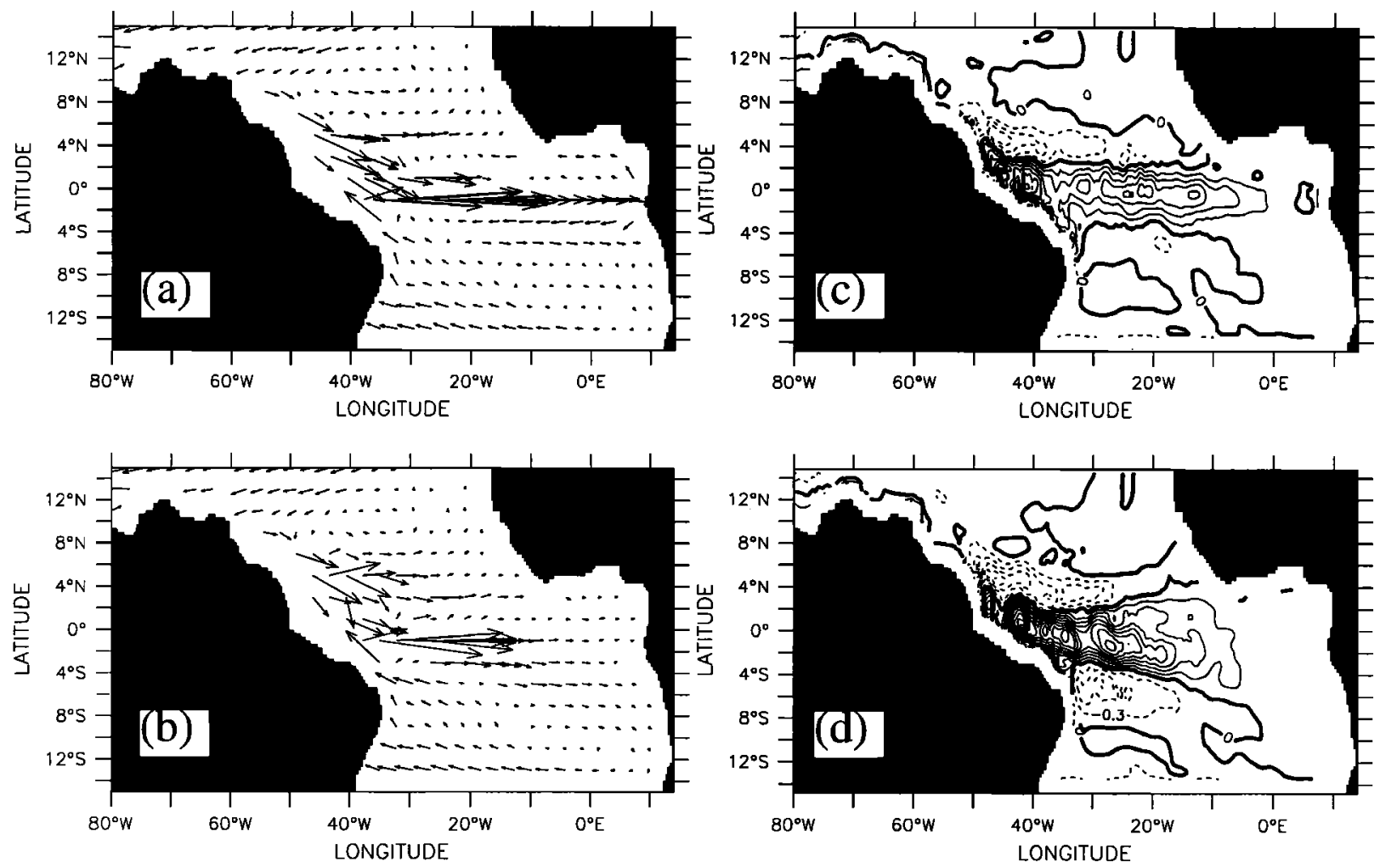

$\longrightarrow 30.0$

Figure 13. Annual mean horizontal velocity at $100 \mathrm{~m}$ for (a) experiment $\mathrm{A}$ and (b) experiment $\mathrm{C}$. The arrows represent averages over seven grid points in the zonal and six points in the meridional direction. The arrow below Figure 13b represents a velocity of $30 \mathrm{~cm} \mathrm{~s}^{-1}$. The corresponding vertical velocities at a depth of $50 \mathrm{~m}$ are also shown for (c) experiment $A$ and (d) experiment $C$. Contour interval is $25 \mathrm{~cm} \mathrm{~d}^{-1}$. 
surements' underestimation of absolute current velocities (Verstraete [1992], refers to an underestimation of EUC velocities of $18 \mathrm{~cm} \mathrm{~s}^{-1}$ ). In the model the EUC is flanked by westward flows at about $2^{\circ} \mathrm{N}$ and $3^{\circ} \mathrm{S}$. These agree well with the geostrophic compensations flows reported by Verstraete [1992], which are, to some extent, visible in the PCM observations but show up more clearly in the density field. These compensation flows carry back thermostad waters westward out of the Gulf of Guinea. There is no evidence of westward return flows in experiment $\mathrm{D}$, which also lacks the pronounced maximum of eastward velocity associated with the EUC.

The simulated horizontal velocity at a depth of $100 \mathrm{~m}$ (i.e., about the depth of the EUC) further reveals (Figure 13) the existence of a strong EUC and westward compensation flows in experiment $A$, whereas run $D$ simulates a broad southeastward flow as continuation of the much weaker EUC. The corresponding upwelling patterns are displayed in Figures 13c and 13d. While in the TKE experiment with the stronger EUC the upwelling is almost symmetrical with respect to the equator, the upwelling region extends in a more southeasterly direction when a constant vertical viscosity is applied below the Kraus-Turner mixed layer. This results in the different regional distribution of primary production in the equatorial Atlantic seen in the TKE experiment A (Plate 1, top) and the Kraus-Turner run D (Plate 2, bottom). The southeastward turning "equatorial" band of high productivity simulated by run D is also found in our test experiment using the TKE scheme with the lower viscosity limit of $K_{m}=10 \mathrm{~cm}^{2} \mathrm{~s}^{-1} \mathrm{im}$ posed (Plate 3).

Associated with the stronger and more realistic EUC flanked by geostrophic westward compensation flows in the TKE experiment is an enhanced meridional tilt of the thermocline in the Gulf of Guinea north of the equator and a strengthened eastward surface flow of the Guinea Current (Figures 12 and 13). In combination with the seasonally varying winds, which are the same [Hellerman and Rosenstein, 1983] in all experiments, this leads to a situation more favorable for coastal upwelling in the TKE experiment. This is illustrated by time and latitude plots of surface chlorophyll and surface temperature along $4^{\circ} \mathrm{W}$ (off Ivory Coast) displayed in Figure 14. Only run A employing the TKE scheme can realistically reproduce the seasonal pattern in surface temperature observed by Houghton and Colin [1987]. Both experiment C using $\star$ constant viscosity coefficient below the Kraus-Turner mixed layer as well as the test experiment employing the same constant viscosity as a minimum viscosity imposed on the TKE scheme fail to reproduce the temperature minumum associated with the coastal upwelling off Ivory Coast between June and September. Overall, meridional temperature gradients and zonal surface currents (not shown) produced by experiment $A$ are much stronger. This holds not only for the coastal upwelling but also for the open ocean upwelling just south of the equator, which along $4^{\circ} \mathrm{W}$ also leads to a local minimum in surface temperature in boreal summer.

The immediate response of the ecosystem model to both coastal and equatorial upwelling events gives rise to elevated concentrations of surface chlorophyll. While all experiments do simulate an equatorial chlorophyll maximum in boreal summer, peak biomass concentrations are generally higher by a factor of 2 in the less viscous TKE experiment. Compared with the runs using a minimum viscosity of $10 \mathrm{~cm}^{2} \mathrm{~s}^{-1}$, the chlorophyll signal of the coastal upwelling off Ivory Coast is more than twice as strong when TKE physics are used.

Clearly, these effects that result from a small change in the parameterization of subgrid-scale viscosity have a local impact only. Apart from the equatorial Atlantic, the primary production simulated in this test experiment (Plate 3) very closely resembles that of the TKE run $A$ without any lower limit on viscosity (Plate 1, top). This is consistent with our hypothesis that the influence of the parameterization of subgrid-scale viscosity will be felt only in regions where ageostrophic effects cannot be neglected.

\section{Choice of the Standard Experiment and Conclusions}

From the above analysis we arrive at the conclusion that unless much finer vertical grids are used, upstream advection is not adequate when modeling processes for which order-of-magnitude changes in vertical diffusion can significantly alter the results. In large regions of the tropical and subtropical thermocline the implicit vertical diffusion inherent in the upstream scheme is much larger than the vertical diffusion deduced from observations. The associated additional diffusive flux of nutrients into the euphotic zone was shown to approximately double primary production when compared to a simulation using a less diffusive, higher-order advection scheme. In the present study the MPDCD scheme was used as an alternative to the too diffusive upstream advection. This is a pragmatic choice that is thought to be a compromise between accuracy and computational economy. More work will be needed to further optimize the representation of tracer advection. For the time being the (approximately) second-order MPDCD advection scheme will be chosen for the baseline run of our eddy-permitting coupled ecosystem-circulation model of the North Atlantic.

The parameterization of diapycnal diffusion has a particularly strong influence on simulated biological production in the subtropical gyre, where the nutricline 

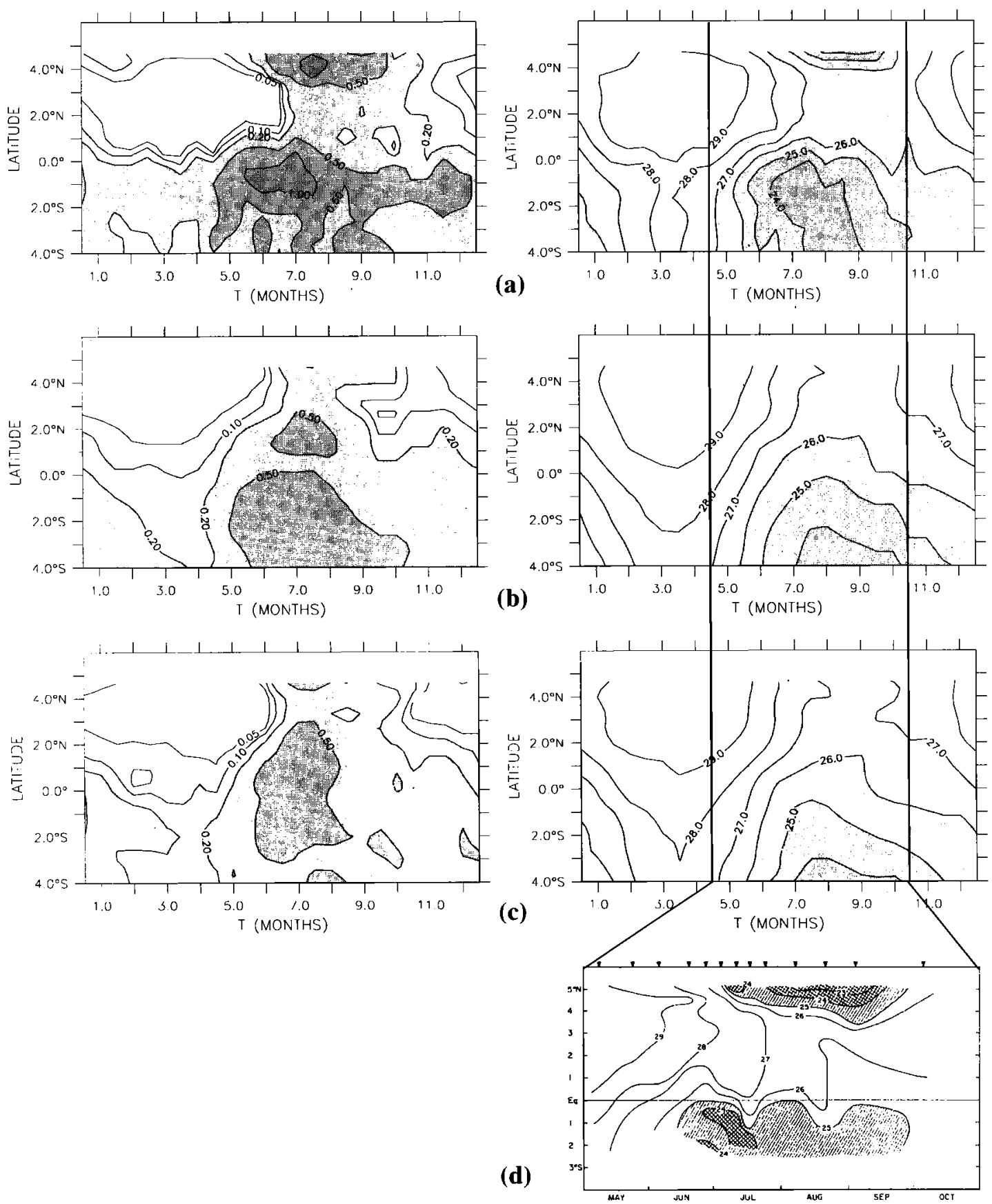

Figure 14. Annual cycle of (left) surface chlorophyll (in $\mathrm{mg} \mathrm{chl} \mathrm{m}^{-3}$ ) and (right) surface temperature (in degrees Celsius) for (a) experiment A with TKE physics; (b) experiment D with Kraus-Turner mixed layer and constant viscosity below the mixed layer; and (c) test experiment with TKE physics, but with viscosity set to $K_{m} \geq 10 \mathrm{~cm}^{2} \mathrm{~s}^{-1}$. (d) Surface temperature as observed by Houghton and Colin [1987]. All quantities are shown along a meridional section at $4^{\circ} \mathrm{W}$ between $4^{\circ} \mathrm{S}$ and Ivory Coast in the north. Vertical averages are taken over the top $23 \mathrm{~m}$. Chlorophyll is diagnosed from the simulated phytoplankton concentration using a constant ratio of $1.59 \mathrm{~g}$ chlorophyll per mol nitrogen. 
lies below the surface mixed layer during all seasons and where Ekman pumping is directed downward. Here primary production varies by a factor of 2 between the runs using a constant vertical diffusivity of $K_{\rho}=0.3 \mathrm{~cm}^{2} \mathrm{~s}^{-1}$ and the alternative expression $K_{\rho}=a N^{-1}$, with $a=$ $5.7 \times 10^{-4} \mathrm{~cm}^{2} \mathrm{~s}^{-2}$, the latter being in better agreement with recent measurements of diapycnal diffusion [e.g., Ledwell et al., 1993].

The close correspondence of experiments A and D in midlatitudes and high latitudes indicates that it is of little importance for the annual mean production whether the mixed layer is infinitely well mixed (Kraus-Turner experiment $D$ ) or whether it is mixed using a finite diffusivity of $O\left(10^{4} \mathrm{~cm}^{2} \mathrm{~s}^{-1}\right)$ typical for the TKE experiment A. Noticeable differences in simulated biological production in the tropical Atlantic were shown to be related to the different vertical viscosities used in experiments A and D. Obviously, the TKE scheme (which Blanke and Delecluse [1993] originally developed and validated for a model of the tropical Atlantic) reproduces the equatorial current system much better than the constant viscosity used in run D. More work would be required to couple the Kraus-Turner model not only with routines that compute ocean-interior diffusivities and handle static instabilities but also with a scheme that yields adequate viscosities below the surface mixed layer. Because the TKE scheme takes care of all these issues in a single routine, it is conceptually more appealing and computationally more efficient (to the extent that one has to store an additional prognostic variable).

Our baseline experiment that emerges from this study is experiment A which combines the higher-order positive definite MPDCD advection scheme with the TKE turbulence closure that was tuned to fit observed diffusivities in the thermocline. This decision has been reached on the basis of physical arguments, by assessing implicit and explicit diffusivities, the representation of the equatorial current system and the surface temperature signal of the upwelling off Ivory Coast. Results of the ecosystem component of the coupled model were shown primarily to demonstrate the biological model's sensitivity to apparently small changes to physics or numerics. This has been done with particular emphasis on annual new and primary production, i.e., quantities most relevant for global nitrogen and carbon cycles. To build some confidence into the overall applicability of our simple pelagic ecosystem model, only a minimum amount of information about biological tracer concentrations and fluxes has been presented. However, there is nothing exceptional about the choice of the ecosystem model or its parameters, so that we may expect that the sensitivity reported here will be similar for alternative configurations of pelagic ecosystem models. A detailed analysis of the ecosystem dynamics of our selected standard experiment will follow in part 2 of our study (A. Oschlies et al., manuscript in preparation, 1998).

\section{Appendix: MPDCD Advection Scheme}

A brief description is given of the multidimensional positive definite centered differences (MPDCD) advection scheme introduced by Lafore et al. [1998]. The local time evolution of a tracer concentration $\Psi$ due to advection can be described in flux form as

$$
\frac{\partial \Psi}{\partial t}=-\nabla \cdot \mathbf{u} \Psi
$$

Using the three-time level leapfrog scheme and assuming a rectangular array of grid boxes, the discrete form of the advection equation for the scalar $\Psi$ reads

$$
\Psi^{t+\Delta t}=\Psi^{t-\Delta t}-2 \Delta t \frac{1}{V} \sum_{i=1}^{6} F_{i}^{t}
$$

where $F_{i}$ is the flux of tracer $\Psi$ through the $i$ th face of the grid box with volume $V$. For a purely advective flux $F_{i}$ can be expressed as $F_{i}=\Psi_{i} u_{i} A_{i}$ with $u_{i}$ and $\Psi_{i}$ denoting normal velocity and tracer value, respectively, on the face with area $A_{i}$. In the high-resolution circulation model we employ biharmonic horizontal diffusion, which itself is not positive definite. Having rewritten the biharmonic diffusion in flux form, this adds diffusive fluxes $D_{i}^{t-\Delta t}$ to the sum in (A2). As usual, diffusive fluxes are evaluated at tirne $t-\Delta t$. To keep the notation simple, we, in the following, use $F_{i}$ to refer to $F_{i}^{t}+D_{i}^{t-\Delta t}$.

A necessary condition for the advection equation yielding positive tracer concentrations at time step $t+\Delta t$ is

$$
\Psi^{t+\Delta t}=\Psi^{t-\Delta t}-2 \Delta t \frac{1}{V}\left(F^{\text {out }}-F^{\mathrm{in}}\right)>0
$$

where $F^{\text {out }} \geq 0$ and $F^{\text {in }} \geq 0$ denote the total outgoing and incoming flux summed over all faces of the grid box. A sufficient criterion for A3 is

$$
2 \Delta t F^{\text {out }} \leq V \Psi^{t-\Delta t}
$$

that is, the outgoing flux $F^{\text {out }}$ is not allowed to remove more tracer in one leapfrog time step than contained in the grid box at the previous time step. To meet the above criterion, a flux limiter ratio $\beta^{\text {out }}$ is introduced:

$$
\beta^{\text {out }}=\frac{V \Psi^{t-\Delta t}}{2 \Delta t F^{\text {out }}}
$$

If $\beta^{\text {out }} \geq 1$, condition (A4) (and hence (A3)) holds and a flux limitation is not needed. If $\beta^{\text {out }}<1$, the outgoing flux $F^{\text {out }}$ is reduced by the flux limiter ratio $\beta^{\text {out }}$. After having computed a $\beta^{\text {out }}$ for each individual grid cell, 
any flux-corrected flux $\hat{F}_{i}$ through the grid box face separating cells $i-1$ and $i$ in the $i$ direction can be written as

$$
\hat{F}_{i}=\min \left(1, \beta_{i-1}^{\text {out }}\right)\left[\max \left(0, F_{i}\right)\right]+\min \left(1, \beta_{i}^{\text {out }}\right)\left[\min \left(0, F_{i}\right)\right]
$$

If the flux is positive, it will be corrected by the limiter ratio $\beta_{i-1}^{\text {out }}$ of cell $i-1$. If the flux is negative, it will be corrected by the flux limiter ratio $\beta_{i}^{\text {out }}$.

By discarding the incoming fluxes, any flux used to compute the set of flux limiter ratios for the entire model grid is used only once as it is associated with a single grid box cell (the one it leaves). Consequently, the above scheme is local and does not need any computationally expensive iterations.

Clearly, the sufficient condition A4 is not a necessary one, making the MPDCD scheme a somewhat pragmatic choice. However, standard tests described by Lafore et al. [1998] as well as our analysis of its numerical diffusivity for a typical tracer disctibution (Figure 4) provide a reasonable level of confidence for its application in the present study.

Acknowledgments. It is a pleasure to acknowledge stimulating discussions with Jean-François Minster and Geoff Evans. We thank Guy Caniaux for bringing the MPDCD advection scheme to our attention. This study was supported through the European Union ESCOBA program (contract ENV4-CT95-0132) and German JGOFS (contract 03F0160D).

\section{References}

Bacastow, R., and E. Maier-Reimer, Dissolved organic carbon in modeling oceanic new production, Global Biogeochem. Cycles, 5, 71-85, 1991.

Barnier, B., L. Siefridt and P. Marchesiello, Surface thermal boundary condition for a global ocean circulation model from a three-year climatology of ECMWF analyses, $J$. Mar. Syst., 6, 363-380, 1995.

Blanke, B., and P. Delecluse, Variability of the tropical Atlantic Ocean simulated by a general circulation model with two different mixed-layer physics, J. Phys. Oceanogr., $23,1363-1388,1993$.

Böning, C. W., and P. Heirmann, On the annual cycle of poleward heat transport in the ocean: Results from highresolution modelling of the North and equatorial Atlantic, J. Phys. Oceanogr., 24, 91-107, 1994.

Böning, C. W., F. O. Bryan, W. R. Holland and R. Döscher, Deep-water formation and meridional overturning in a high-resolution model of the North Atlantic, J. Phys. Oceanogr., 26, 1142-1164, 1996.

Bryan, F. O., and W. R. Holland, A high resolution simulation of the wind- and thermohaline-driven circulation in the North Atlantic Ocean, in Parameterization of Small Scale Processes, edited by P. Müller and D. Henderson, Spec. Publ., pp. 99-115, Hawaii Inst. of Geophys., Manoa, 1989.

Camp, N. T., and R. L. Elsberry, Oceanic thermal response to strong atmospheric forcing, 2, The role of onedimensional processes, J. Phys. Oceanogr., 8, 215-224, 1978.
Conkright, M. E., S. Levitus, and T. P. Boyer, World Ocean Atlas 1994, volume 1, Nutrients, Natl. Environ. Satell. Data and Inf. Serv., Natl. Oceanic and Atmos. Admin., Silver Spring, Md., 1994.

Crawford, W. R., Pacific equatorial turbulence, J. Phys. Oceanogr., 12, 1137-1149, 1982.

Dadou, I., V. Garçon, V. Andersen, G. R. Flierl, and C. S. Davis, Impact of the North Equatorial Current meandering on a pelagic ecosystem: A modeling approach, J. Mar. Res., 54, 311-342, 1996.

Döscher, R., C. W. Böning, and P. Herrmann, Response of circulation and heat transport in the North Atlantic to changes in thermohaline forcing in northern latitudes: a model study, J. Phys. Oceanogr., 24, 2306-2320, 1994.

Esbensen, S. K., and Y. Kushnir, The Heat Budget of the Global Ocean: An Atlas Based on Estimates From Surface Marine Observations, Oreg. State Univ., Corvallis, 1981.

Evans, G. T., and J. S. Parslow, A model of annual plankton cycles, Biol. Oceanogr., 3, 328-347, 1985.

Farrow, D. E., and D. P. Stevens, A new tracer advection scheme for Bryan and Cox type ocean general circulation model, J. Phys. Oceanogr., 25, 1731-1741, 1995.

Fasham, M. J. R., Variations in the seasonal cycle of biological production in subarctic oceans: A model sensitivity analysis, Deep Sea Res., Part I, 42, 1111-1149, 1995.

Fasham, M. J. R., H. W. Ducklow, and S. M. McKelvie, A nitrogen-based model of plankton dynamics in the oceanic mixed layer, J. Mar. Res., 48, 591-639, 1990.

Fasham, M. J. R., J. L. Sarmiento, R. D. Slater, H. W. Ducklow, and R. Williams, Ecosystem behavior at Bermuda Station "S" and Ocean Weather Station "India": a general circulation model and observational analysis, Global Biogeochem. Cycles, 7, 379-415, 1993.

Gardner, W. D., I. D. Walsh, and M. J. Richardson, Biophysical forcing of particle production and distribution during a spring bloom in the North Atlantic, Deep Sea Res., Part II, 40, 171-195, 1993.

Gargett, A. E., Vertical eddy diffusivity in the ocean interior, J. Mar. Res., 42, 359-393, 1984.

Gaspar, P., Modelling the seasonal cycle of the upper ocean, J. Phys. Oceanogr., 18, 161-180, 1988.

Gaspar, P., Y. Gregoris, and J.-M. Lefevre, A simple eddy kinetic energy model for simulations of the oceanic vertical mixing: tests at station Papa and Long-Term Upper Ocean Study site, J. Geophys. Res., 95, 16,179-16,193, 1990.

Gerdes, R., C. Köberle, and J. Willebrand, The influence of numerical advection schemes on the results of ocean general circulation models, Clim. Dyn., 5, 211-226, 1991.

Han, Y.-J., A numerical world oceancirculation model, II, A baroclinic experiment, Dyn. Atmos. Oceans, 8, 141-172, 1984.

Haney, R. L., Surface thermal boundary condition for ocean circulation models, J. Phys. Oceanogr., 1, 241-248, 1971.

Hecht, M. W., F. O. Bryan, and W. R. Holland, A consideration of tracer advection schemes in a primitive equation ocean model, J. Geophys. Res., 103, 3301-3321, 1998.

Hellerman, S., and M. Rosenstein, Normal monthly wind stress over the World Ocean with error estimates, J. Phys. Oceanogr., 13, 1093-1104, 1983.

Houghton, R. W., and C. Colin, Wind-driven meridional eddy heat flux in the Gulf of Guinea, J. Geophys. Res., $92,10,777-10,786,1987$.

Hurtt, G. C., and R. A. Armstrong, A pelagic ecosystem model calibrated with BATS data, Deep Sea Res., Part II, 43, 653-683, 1996. 
Jerlov, N. G., Optical Oceanography, 194 pp, Elsevier, New York, 1968.

Käse, R. H., Modeling the oceanic mixed layer and effects of deep convection, in Buoyant convection in Geophysical Flows, edited by E. J. Plate et al., pp 157-183, Kluwer Academic Publ., Norwell, Mass. , 1998.

Kraus, E. B., and J. S. Turner, A one-dimensional model of the seasonal thermocline, II, The general theory and its consequences, Tellus, 19, 98-106, 1967.

Lafore, J.-P., et al., The Meso-NH atmospheric simulation system, I, Adiabatic formulation and control simulations. Ann. Geophys., 16, 90-109, 1998.

Ledwell, J. R., A. J. Watson, and C. S. Law, Evidence for slow mixing across the pycnocline from an open-ocean tracer-release experiment, Nature, 364, 701-703, 1993.

Leonard, B. P., A stable and accurate convective modelling procedure based on quadratic upstream interpolation, Comput. Methods Appl. Mech. Eng., 19, 59-98, 1979.

Levitus, S., Climatological atlas of the world ocean. NOAA Prof. Pap. 13, 173 pp, U.S. Gov. Print. Off., Washington, D.C., 1982.

Matear, R. J., and G. Holloway, Modeling the inorganic phosphorus cycle of the North Pacific using an adjoint data assimilation model to assess the role of dissolved organic phosphorus, Global Biogeochem. Cycles, 9, 101$119,1995$.

McGillicuddy, D. J. Jr., and A. R. Robinson, Eddy-induced nutrient supply and new production in the Sargasso Sea, Deep Sea Res., Part I, 44, 1427-1450, 1997.

Monterey, G., and S. Levitus, Seasonal variability of mixed layer depth for the World Ocean, NESDIS Atlas 14, Natl. Oceanic aand Atmos. Admin., Silver Spring, Md., 1997.

Najjar, R. G., J. L. Sarmiento, and J. R. Toggweiler, Downward transport and fate of organic matter in the ocean: Simulations with a general circulation model, Global Biogeochem. Cycles, 6, 45-76, 1992.

Niiler, P. P., and E. B. Kraus, One-dimensional models of the upper ocean, in Modelling and Prediction of the Upper Layers of the Ocean, edited by E. B. Kraus, pp. 143-172, Pergamon, Tarrytown, N.Y., 1977.

Oschlies, A., On spurious interactions between mixed layer model, convective adjustment, and isopycnal mixing in ocean circulation models, Mon. Weather Rev., in press, 1998.

Oschlies, A., and V. Garçon, Eddy induced enhancement of primary production in a model of the North Atlantic Ocean, Nature, 394, 266-269, 1998.

Pacanowski, R., K. Dixon, and A. Rosati, The G.F.D.L Modular Ocean Model users guide version 1, Techn. Rep. 2, GFDL Ocean Group, Geophys. Fluid Dyn. Lab., Princeton, N.J., 1991.

Paillet, J., and M. Arhan, Shallow pycnoclines and mode water subduction in the Eastern North Atlantic, J. Phys. Oceanogr., 26, 96-114, 1996.
Paulson, C. A., and J. J. Simpson, Irradiance measurements in the upper ocean, J. Phys. Oceanogr., 7, 952-956, 1977.

Price, J. F., R. A. Weller, and R. Pinkel, Diurnal cycling: Observations and models of the upper ocean response to diurnal heating, cooling, and wind mixing, $J$. Geophys. Res., 91, 8411-8427, 1986.

Roemmich, D., The balance of geostrophic and Ekman transports in the tropical Atlantic Ocean, J. Phys. Oceanogr., 13, 1534-1539, 1983.

Sarmiento, J. L., R. D. Slater, M. J. R. Fasham, H. W. Ducklow, J. R. Toggweiler, and G. T. Evans, A seasonal threedimensional ecosystem model of nitrogen cycling in the North Atlantic euphotic zone, Global Biogeochem. Cycles, 7, 417-450, 1993.

Stammer, D., and C. W. Böning, Mesoscale varibility in the Atlantic Ocean from GEOSAT Altimetry and WOCE high resolution numerical modeling, J. Phys. Oceanogr., 22, 732-752, 1992.

Sterl, A., and A. Kattenberg, Embedding a mixed layer model into an ocean general circulation model of the Atlantic: The importance of surface mixing for heat flux and temperature, J. Geophys. Res., 99, 14,139-14,157, 1994.

Sugimura, Y., and Y. Suzuki, A high-temperature catalytic oxidation method for the determination of non-volatile dissolved organic carbon in seawater by direct injection of a liquid sample, Mar. Chem., 24, 105-131, 1988.

Suzuki, Y., On the measurement of DOC and DON in seawater, Mar. Chem., 41, 287-288, 1993.

Sverdrup, H. U., On the conditions for the vernal blooming of phytoplankton, Cons. Perm. Int. Explor. Mer., 18, 287-295, 1953.

Verstraete, J.-M., The seasonal upwelling in the Gulf of Guinea, Prog. Oceanogr., 29, 1-60, 1992.

von Liebig, J., 1840: Organic Chemistry in its Applications to Agriculture and Physiology, $387 \mathrm{pp}$, Taylor and Walton, London, 1840.

Wacongne, S., Dynamical regimes of a fully nonlinear stratified model of the Atlantic equatorial undercurrent, J. Geophys. Res., 94, 4801-4815, 1989.

Watson, A. J., C. Robinson, J. E., Robertson, P. J. L. Williams, and M. J. R. Fasham, Spatial variability in the sink for atmospheric carbon dioxide in the North Atlantic, Nature, 350, 50-53, 1991.

V. Garçon, Centre National de la Recherche Scientifique, UMR5566/LEGOS, 18 Avenue Edouard Belin,31401 Toulouse Cedex 4, France. (e-mail: garcon@pontos.cst.cnes.fr

A. Oschlies, Institut für Meereskunde an der Universität Kiel, Düsternbrooker Weg 20, 24105 Kiel, Germany. (e-mail: aoschlies@ifm.uni-kiel.de)

(Received December 12, 1997; revised June 24, 1998; accepted August 27, 1998.) 